\title{
Recent advances in the use of PI3K inhibitors for glioblastoma multiforme: current preclinical and clinical development
}

\author{
Hua-fu Zhao ${ }^{1,2}$, Jing Wang ${ }^{2}$, Wei Shao ${ }^{3}$, Chang-peng Wu ${ }^{4,1}$, Zhong-ping Chen², Shing-shun Tony To $^{3 *}$ \\ and Wei-ping $\mathrm{Li}^{1 *}$
}

\begin{abstract}
Glioblastoma multiforme (GBM) is the most common and aggressive malignant primary tumor in the central nervous system. One of the most widely used chemotherapeutic drugs for GBM is temozolomide, which is a DNA-alkylating agent and its efficacy is dependent on MGMT methylation status. Little progress in improving the prognosis of GBM patients has been made in the past ten years, urging the development of more effective molecular targeted therapies. Hyper-activation of the phosphatidylinositol 3-kinase (PI3K)/Akt pathway is frequently found in a variety of cancers including GBM, and it plays a central role in the regulation of tumor cell survival, growth, motility, angiogenesis and metabolism. Numerous PI3K inhibitors including pan-PI3K, isoform-selective and dual PI3K/mammalian target of rapamycin (MTOR) inhibitors have exhibited favorable preclinical results and entered clinical trials in a range of hematologic malignancies and solid tumors. Furthermore, combination of inhibitors targeting PI3K and other related pathways may exert synergism on suppressing tumor growth and improving patients' prognosis. Currently, only a handful of PI3K inhibitors are in phase I/II clinical trials for GBM treatment. In this review, we focus on the importance of PI3K/Akt pathway in GBM, and summarize the current development of PI3K inhibitors alone or in combination with other inhibitors for GBM treatment from preclinical to clinical studies.
\end{abstract}

Keywords: Glioblastoma, GBM, PI3K, mTOR

\section{Background}

Glioblastoma multiforme (GBM), classified as WHO grade IV glioma, is the most common, aggressive and malignant primary tumor in the central nervous system [1]. The incidence rate of GBM is the highest in malignant brain tumors, with 3.19 new cases per 100,000 populations per year $[1,2]$. Glioblastoma is characterized by rapid growth, extensive infiltration to neighboring brain tissues, pseudopalisading necrosis and angiogenesis, which contribute to poor prognosis. Despite the standard treatment including maximal surgical resection followed by adjuvant radiotherapy and chemotherapy, the prognosis of GBM patients remains poor. The 2-year relative survival rate for

\footnotetext{
* Correspondence: tony.to@polyu.edu.hk; wpli@szu.edu.cn

${ }^{3}$ Department of Health Technology and Informatics, The Hong Kong Polytechnic University, Hong Kong, China

'Department of Neurosurgery \& Shenzhen Key Laboratory of Neurosurgery, the First Affiliated Hospital of Shenzhen University, Shenzhen Second People's Hospital, Shenzhen 518035, China

Full list of author information is available at the end of the article
}

GBM patients is approximately $26.5 \%$, and the median overall survival is 14.6 months [3].

Genetic aberrations in glioblastoma including EGFR, PDGFRA, PIK3CA, PTEN, TP53 and CDKN2A/B etc., drive the dysfunction of signaling pathways such as PI3K/Akt/mTOR, p53 and RB1 pathways, and open up possible therapies for GBM by targeting these pathways with selective inhibitors [4]. The phosphatidylinositol 3-kinases (PI3Ks)/Akt signaling pathway plays a central role in the regulation of signal transduction, which mediates various biological processes including cell proliferation, apoptosis, metabolism, motility and angiogenesis in GBM. Generally, activation of PI3K/Akt pathway starts with activation of receptor tyrosine kinases (RTKs) or G protein-coupled receptors (GPCRs). Class $\mathrm{I}_{\mathrm{A}}$ and $\mathrm{I}_{\mathrm{B}}$ PI3Ks mainly respond to the activation of RTKs and GPCRs, respectively. Epidermal growth factor receptor (EGFR, ErbB-1), a transmembrane protein, belongs to a RTK subfamily - ErbB family. After binding to its ligand EGF, 
EGFR undergoes a transition from an inactive monomeric form to an active homodimer. Its variant III mutation (EGFRvIII), characterized by an in-frame deletion in exons $2-7$, is common $(25 \%-50 \%)$ in $\mathrm{GBM}$ and produces a truncated EGFR protein without the extracellular ligand-binding domain, leading to its ligand-independent constitutive activation [5]. A simplified schematic diagram showing PI3K/Akt signaling is presented in Fig. 1. When a ligand such as EGF or PDGF binds to its corresponding RTK, the intracellular C-terminal kinase domain of RTK undergoes conformational alterations and autophosphorylation, which provides binding sites for the regulatory subunits of PI3K. The interaction between RTK and PI3K regulatory subunits subsequently relieves the inhibitory effect on the catalytic subunits, leading to elevated lipid kinase activity of PI3K. Activation of PI3K transforms phosphatidylinositol 4,5-bisphosphate (PtdIns(4,5)P2, PIP2) to phosphatidylinositol 3,4,5-triphosphate (PtdIns(3,4,5)P3, PIP3) in plasma membrane. Subsequently, PIP3 binds to Akt and anchors it to the plasma membrane. Akt at Thr308 and Ser473 residues are then phosphorylated by phosphoinositide-dependent kinase -1 (PDK-1) and mammalian target of rapamycin complex 2 (mTORC2), respectively, leading to its complete activation. PTEN (phosphatase and tensin homolog deleted on chromosome 10) and PHLPP (PH domain and leucine rich repeat protein phosphatase) are two tumor suppressors, the former transforms PIP3 to PIP2 and blocks the recruitment of Akt to the plasma membrane, while the latter dephosphorylates Ser473 in Akt and subsequently suppresses Akt activation [6, 7]. Activated Akt, in turn, phosphorylates downstream pathway molecules to mediate metabolism, cell growth, angiogenesis, motility and apoptosis [8]. It mediates protein synthesis by phosphorylating tuberous sclerosis complex (TSC) and then activating mTOR. mTOR and its partner Raptor (mTORC1) bind to p70 $\mathrm{S} 6 \mathrm{~K}$ and eukaryotic initiation factor 4E-binding protein 1 (4EBP1), leading to their phosphorylation and initiation of protein translation [9].

Hyper-activation of PI3K/Akt pathway confers rapid growth, tumor progression and multidrug resistance upon GBM cells. Inhibition of PI3K alone or in combination with other molecules may result in GBM cell death and retarded tumor progression. Here, we summarize the roles of PI3K in GBM and highlight recent advances and challenges in the development of PI3K inhibitors as

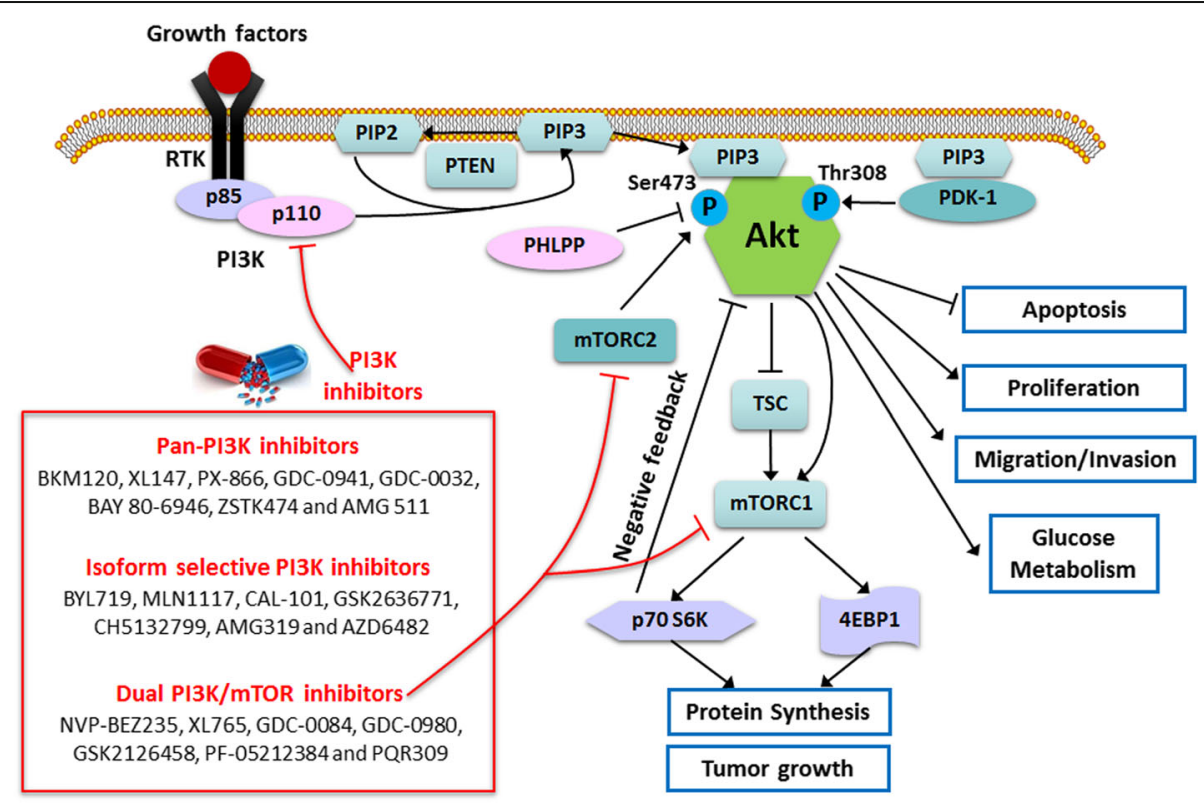

Fig. 1 Schematic diagram of PI3K/Akt/mTOR signaling pathway and relevant PI3K inhibitors. When the growth factors bind to their corresponding RTKs, the regulatory isoform of PI3K ( $p 85$ ) binds to RTKs and relieves its inhibition on the catalytic isoform ( $\mathrm{p} 110)$, leading to the activation of PI3K. PI3K gives rise to the production of the lipid messenger PIP3 from PIP2, which can be reversed by the tumor suppressor PTEN. Subsequently, PIP3 binds to the PH domain of Akt and recruits Akt to the plasma membrane. PDK-1 is also recruited by PIP3 to the plasma membrane through its PH domain, and then phosphorylates Akt at Thr308. Akt is completely activated through phosphorylation at Ser473 by mTORC2 (PDK-2). PHLPP is able to dephosphorylate Akt at Ser473. Activated Akt phosphorylates a variety of downstream pathway molecules to facilitate tumor cell survival, proliferation, migration, invasion and glucose metabolism. The Akt downstream mTORC1 axis also regulates protein synthesis and cell growth. The tumor suppressor TSC1 and TSC2 are two substrates of Akt, and their phosphorylation leads to the blockade of their inhibitory effects on mTORC1. Activated mTORC1 then phosphorylates 4EBP1 and p70 S6 K, resulting in the initiation of protein translation. Activation of mTORC1 also triggers a negative feedback to suppress Akt phosphorylation. Numerous PI3K inhibitors have been developed to target PI3K Akt/mTOR signaling. Pan-PI3K and isoform-selective PI3K inhibitors suppress the activities of p110 catalytic isoforms, while PI3K/mTOR inhibitors block the activation of both $\mathrm{p} 110$ and $\mathrm{mTORC} 1 / 2$ 
targeted therapeutic agents for GBM. The most recent experimental, preclinical and clinical studies are presented to emphasize the prospect of PI3K inhibitors for GBM treatment.

\section{Roles of PI3K catalytic isoforms in glioblastoma}

Class $\mathrm{I}_{\mathrm{A}}$ PI3K is composed of a heterodimer consisting of a $110 \mathrm{kDa}$ catalytic subunit (p110 $\alpha, \mathrm{p} 110 \beta$ and $\mathrm{p} 110 \delta$ ) and an $85 \mathrm{kDa}$ regulatory subunit [8]. The regulatory p84/p101 and catalytic p110 $\gamma$ subunits form the only member in the class $\mathrm{I}_{\mathrm{B}}$ PI3K. The $\mathrm{p} 110 \alpha$ and $\mathrm{p} 110 \beta$ isoforms are ubiquitously expressed, whereas p110 $\delta$ and $\mathrm{p} 110 \gamma$ are primarily expressed in leukocytes. The $\mathrm{p} 110 \alpha$, p $110 \beta$ and $110 \delta$ isoforms exhibit distinct roles in different pathological processes in cancer cells. The p110 $\alpha$ isoform is required for tumor cell proliferation, migration and invasion, whereas p110 $\beta$ is essential to cell survival and tumorigenesis [10-12].

Compared to PTEN or EGFR mutations, mutations of PIK3CA (encodes $\mathrm{p} 110 \alpha$ ) in 10 of 20 exons are less frequent but very important in GBM, ranging from $4 \%$ to 27\% [13-16]. Whole genome sequencing of TCGA GBM samples shows that $18.3 \%$ of GBM exhibit PIK3CA and PIK3R1 mutations, which are mutually exclusive of PTEN mutation or deletion [4]. The majority of PIK3CA mutants (including the hot-spot mutations in exon 9 and 20) show gain of PI3K function and promote the recruitment of p110 $\alpha$ to membrane phospholipids, leading to the constitutive activation of $\mathrm{p} 110 \alpha$ and Akt [17]. Therefore, $\mathrm{p} 110 \alpha$ may be a promising target for GBM treatment when harboring PIK3CA mutation. Accumulating studies demonstrate that $\mathrm{p} 110 \alpha$ plays a critical role in tumorigenesis and progress of GBM. Knockdown of PIK3CA significantly inhibits cell viability, migration and invasion in GBM cells through decreasing Akt and FAK activation [11]. In addition, GBM cell growth, survival and migration are effectively suppressed in vitro by the $\mathrm{p} 110 \alpha$ isoform-selective inhibitors A66 or PIK-75 [18-20].

Although somatic mutations of the p110 $\beta$ isoform have rarely been identified in GBM and other cancers, clinical studies show that overexpression of $\mathrm{p} 110 \beta$ is found in $15 \%$ of invasive breast cancer ( 48 of 315 cases) and $28 \%$ of colorectal cancer ( 23 of 82 cases), and is correlated with poor overall survival, with one study showing that $\mathrm{p} 110 \beta$ overexpression is barely detected in GBM samples ( 1 of 74 cases) [20-22]. In contrast to the patient samples, p110 $\beta$ overexpression is frequently found in a series of GBM cell lines [20, 23]. Nevertheless, p110 $\beta$ plays a crucial role in GBM cell growth, survival and migration in the context of PTEN loss. Knockdown of $P I K 3 C B$ (encodes p110ß) suppresses cell proliferation and induces caspase-dependent apoptosis in GBM in vitro and in vivo, and it synergizes with PTEN restoration
[23, 24]. However, PIK3CB knockdown barely suppresses GBM cell migration [23]. On the contrary, inhibition of $\mathrm{p} 110 \beta$ using the selective inhibitor TGX-221 significantly suppresses cell migration in GBM cells, with little inhibitory effect on GBM cell survival and invasion $[19,20]$. These findings suggest a kinase-independent function of $\mathrm{p} 110 \beta$ and a competition model that $\mathrm{p} 110 \beta$ modulates PI3K activity by competing against $\mathrm{p} 110 \alpha$ for RTK binding in GBM [25]. Moreover, PTEN-deficient tumor growth depends on $\mathrm{p} 110 \beta$ rather than $\mathrm{p} 110 \alpha$, suggesting that targeting $p 110 \beta$ may be an option for the treatment of PTEN-deficient GBM [26].

Due to the high expression level in leukocytes, the p110 $\delta$ and p110y subunits are promising therapeutic targets for hematologic malignancies including leukemia, lymphoma and multiple myeloma [27, 28]. Recently, overexpression of $\mathrm{p} 110 \delta$ is also observed in solid tumors such as GBM, neuroblastoma, breast and prostate cancers, indicating that inhibition of p110 $\delta$ may also be an attractive option for GBM treatment [23, 29, 30]. Our previous study shows that $\mathrm{p} 110 \delta$ is overexpressed in $50 \%$ of high grade glioma cell lines (6 of 12), and knockdown of p110 inhibits migration and invasion of GBM cells by decreasing focal adhesion kinase (FAK) expression [23]. However, inhibition of p110 $\delta$ by its selective inhibitor CAL-101 moderately impairs GBM cell proliferation and migration, but it doesn't significantly suppress tumor growth in GBM xenograft mouse model [19]. These findings indicate that targeting p110 $\delta$ may not be an effective approach for GBM treatment. On the other hand, accumulating evidence indicates that p110y is also involved in the development and progression of solid tumors. CXCR4-induced activation of p110y leads to increased migration, invasion and metastasis of melanoma and breast cancer cells [31, 32]. A sensitized RNA interference screen identifies that p110y is vital to medulloblastoma cell proliferation and confer resistance of these cells to cisplatin [33]. Unfortunately, to date there is no study describing the role of p110y in GBM.

\section{PI3K inhibitors and their therapeutic potentials for GBM} According to their isoform selectivity, PI3K inhibitors are generally classified into pan-PI3K, isoform-selective and dual PI3K/mTOR inhibitors. Currently, more than 50 PI3K inhibitors have been designed and produced for cancer treatment. Characteristics and structural formulas of the most commonly used and novel PI3K inhibitors are listed in Tables 1 and 2. However, only a handful of them such as BKM120, XL147 and XL765 have successfully entered into clinical trials for GBM treatment. The prevalent PI3K inhibitors with great potential in clinical practice for GBM are discussed below. 
Table 1 Characteristics of novel PI3K inhibitors

\begin{tabular}{|c|c|c|c|c|c|c|c|c|}
\hline \multirow[t]{2}{*}{ Classification } & \multirow[t]{2}{*}{ Drug name } & \multicolumn{5}{|c|}{$\mathrm{IC}_{50}(\mathrm{nM})$} & \multirow{2}{*}{$\mathrm{I}_{50}$ to GBM cells $(\mu \mathrm{M})$} & \multirow[t]{2}{*}{ Reference } \\
\hline & & $\mathrm{p} 110 \mathrm{a}$ & $\mathrm{p} 110 \beta$ & p1108 & p110y & $\mathrm{mTORC} 1 / 2$ & & \\
\hline \multirow[t]{8}{*}{ Pan-PI3K inhibitors } & Pictilisib (GDC-0941) & 3 & 33 & 3 & 75 & 580 & 0.95 (U-87 MG) & {$[63,130]$} \\
\hline & Taselisib (GDC-0032) & 0.29 & 9.1 & 0.12 & 0.97 & 1200 & N/A & [131] \\
\hline & Buparlisib (BKM120) & 52 & 166 & 116 & 262 & 4600 & $\begin{array}{l}1.28 \pm 0.33 \text { (p53 wt cells) } \\
2.08 \pm 0.69 \text { (p53 mutant/deleted cells) }\end{array}$ & {$[35,36]$} \\
\hline & Pilaralisib (XL147, SAR245408) & 39 & 383 & 36 & 23 & $>15,000$ & $\begin{array}{l}24.0(\mathrm{U}-87 \mathrm{MG}) \\
>30.0(\mathrm{U}-251 \text { and } \mathrm{U}-373 \mathrm{MG})\end{array}$ & [43] \\
\hline & Copanlisib (BAY 80-6946) & 0.5 & 3.7 & 0.7 & 6.4 & 45 & $\sim 0.1$ (U-87 MG) & {$[73,132]$} \\
\hline & Sonolisib (PX-866) & 0.1 & $>300$ & 2.9 & N/A & N/A & N/A & [52] \\
\hline & ZSTK474 & 16 & 44 & 4.6 & 49 & $>10,000$ & $\begin{array}{l}7.0 \text { (U-87 MG) } \\
1.1 \text { (U-251 MG) }\end{array}$ & {$[68,133]$} \\
\hline & AMG 511 & 4 & 6 & 2 & 1 & N/A & N/A & [70] \\
\hline \multirow{7}{*}{$\begin{array}{l}\text { Isoform-selective } \\
\text { inhibitors }\end{array}$} & Alpelisib (BYL719) & 5 & 1200 & 290 & 250 & $>9100$ & N/A & [75] \\
\hline & Idelalisib (CAL-101, GS-1101) & 820 & 565 & 2.5 & 89 & $>1000$ & 39.11 (U-87 MG) & {$[19,134]$} \\
\hline & AMG319 & 3300 & 2700 & 18 & 850 & N/A & N/A & [135] \\
\hline & AZD6482 & 870 & 10 & 80 & 1090 & N/A & N/A & [136] \\
\hline & CH5132799 & 14 & 120 & 500 & 36 & 1600 & N/A & [137] \\
\hline & AS-605240 & 60 & 270 & 300 & 8 & N/A & N/A & [138] \\
\hline & MLN1117 (INK1117) & 15 & 4500 & 1900 & 13,390 & 1670 & N/A & [139] \\
\hline \multirow{11}{*}{$\begin{array}{l}\text { Dual PI3K/mTOR } \\
\text { inhibitors }\end{array}$} & Dactolisib (NVP-BEZ235) & 4 & 75 & 7 & 5 & 6 & $0.04-0.1$ & {$[89,140]$} \\
\hline & NVP-BGT226 & 4 & 63 & N/A & 38 & N/A & N/A & [141] \\
\hline & Omipalisib (GSK2126458, GSK458) & 0.019 & 0.13 & 0.024 & 0.06 & $0.18 / 0.3$ & N/A & [142] \\
\hline & GSK1059615 & 0.4 & 0.6 & 2 & 5 & 12 & N/A & [143] \\
\hline & Voxtalisib (XL765, SAR245409) & 39 & 113 & 41 & 9 & $160 / 910$ & $\begin{array}{l}2.6 \text { (U-87 MG) } \\
19.6 \text { (U-251 MG) } \\
>30 \text { (U-373 MG) }\end{array}$ & [100] \\
\hline & Apitolisib (GDC-0980) & 5 & 27 & 7 & 14 & 17 & N/A & [144] \\
\hline & GDC-0084 (RG7666) & 2 & 46 & 3 & 10 & 70 & $0.74(U-87 \mathrm{MG})$ & [104] \\
\hline & VS-5584 (SB2343) & 16 & 68 & 42 & 25 & 37 & $0.18(U-87 \mathrm{MG})$ & [145] \\
\hline & PF-04691502 & 1.8 & 2.1 & 1.6 & 1.9 & 16 & N/A & [146] \\
\hline & $\begin{array}{l}\text { Gedatolisib (PF-05212384, } \\
\text { PKI-587) }\end{array}$ & 0.4 & N/A & N/A & 5.4 & 1.6 & N/A & [147] \\
\hline & PKI-402 & 2 & 7 & 14 & 16 & 3 & 0.077 (U-87 MG) & [148] \\
\hline
\end{tabular}

N/A, not available

\section{Pan-PI3K inhibitors}

The first generation of pan-PI3K inhibitors wortmannin and LY294002, that target all class $\mathrm{I}_{\mathrm{A}}$ p110 isoforms, are of limited use clinically due to their poor pharmaceutical properties (insolubility and short half-life), off-target effects and unacceptable toxicities in animal studies [34]. A new generation of pan-PI3K inhibitors with improved safety, efficacy and pharmacokinetics such as BKM120, XL147, PX-866, GDC-0941 and GDC-0032 have been developed and have entered into clinical trials (Table 3 ).

\section{BKM120}

Buparlisib (NVP-BKM120, BKM120) is an orally bioavailable pan-PI3K inhibitor against all p110 isoforms with half maximal inhibitory concentration $\left(\mathrm{IC}_{50}\right)$ of $52-$ 262 nM. Its half-life across species in mouse, rat, dog and monkey is $1.6,11,6.6$ and $3.6 \mathrm{~h}$, respectively [35]. BKM120 induces $G_{2} / M$ cell cycle arrest and apoptosis in GBM cells through microtubule misalignment and mitotic dysfunction in a p53-dependent manner [36]. It also promotes tumor necrosis factor-related apoptosis inducing ligand (TRAIL)- and Bcl-2 inhibitor-induced apoptosis in GBM cells via elevated Noxa expression, sequestration of Mcl-1 by Noxa and release of proapoptotic protein Bim and Bak from Mcl-1 [37, 38]. Furthermore, preclinical studies show that BKM120 impedes intracerebral U-87 MG GBM cell xenograft growth and prolongs survival of animals harboring 
Table 2 Structural formulas of PI3K inhibitors

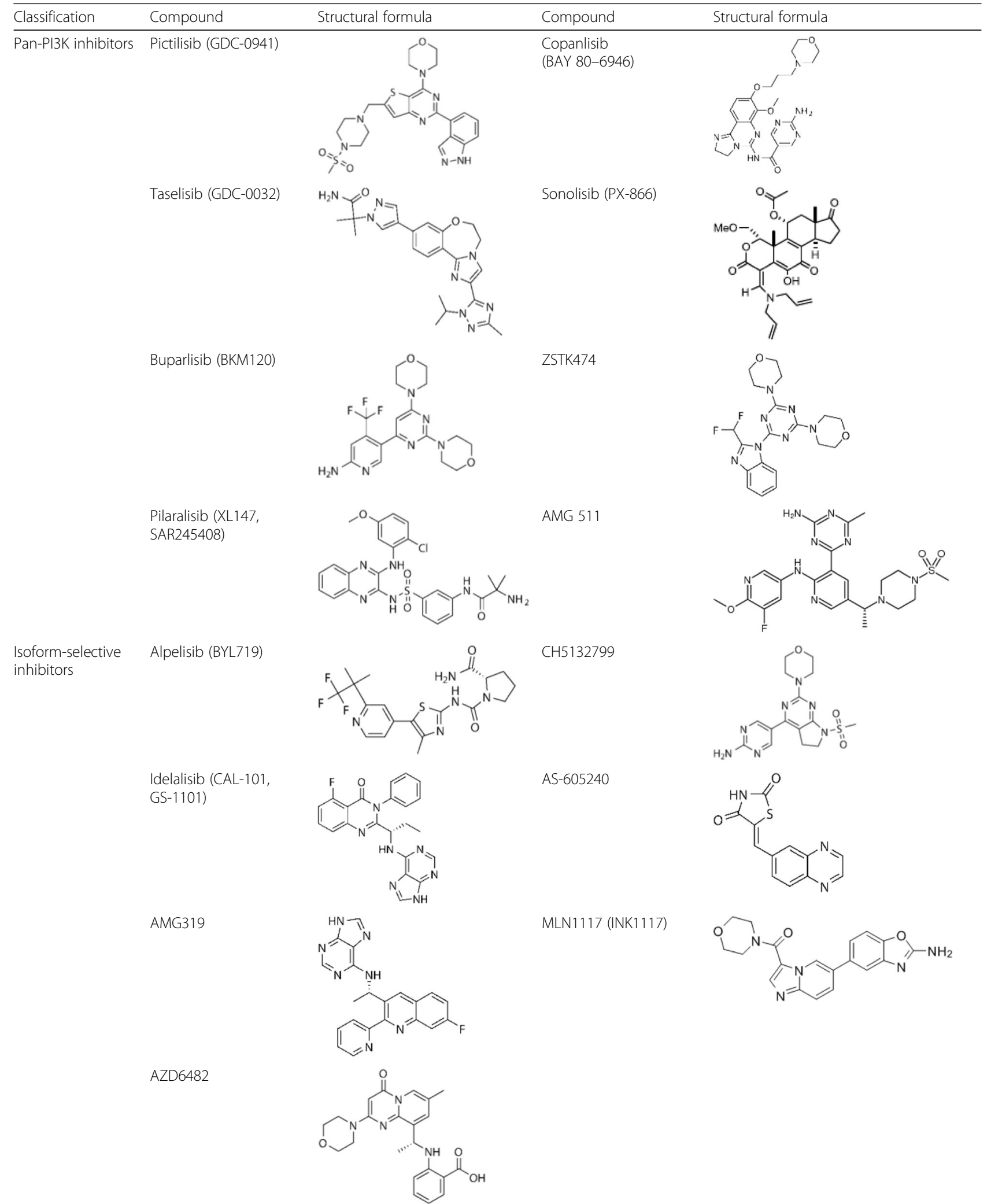


Table 2 Structural formulas of PI3K inhibitors (Continued)

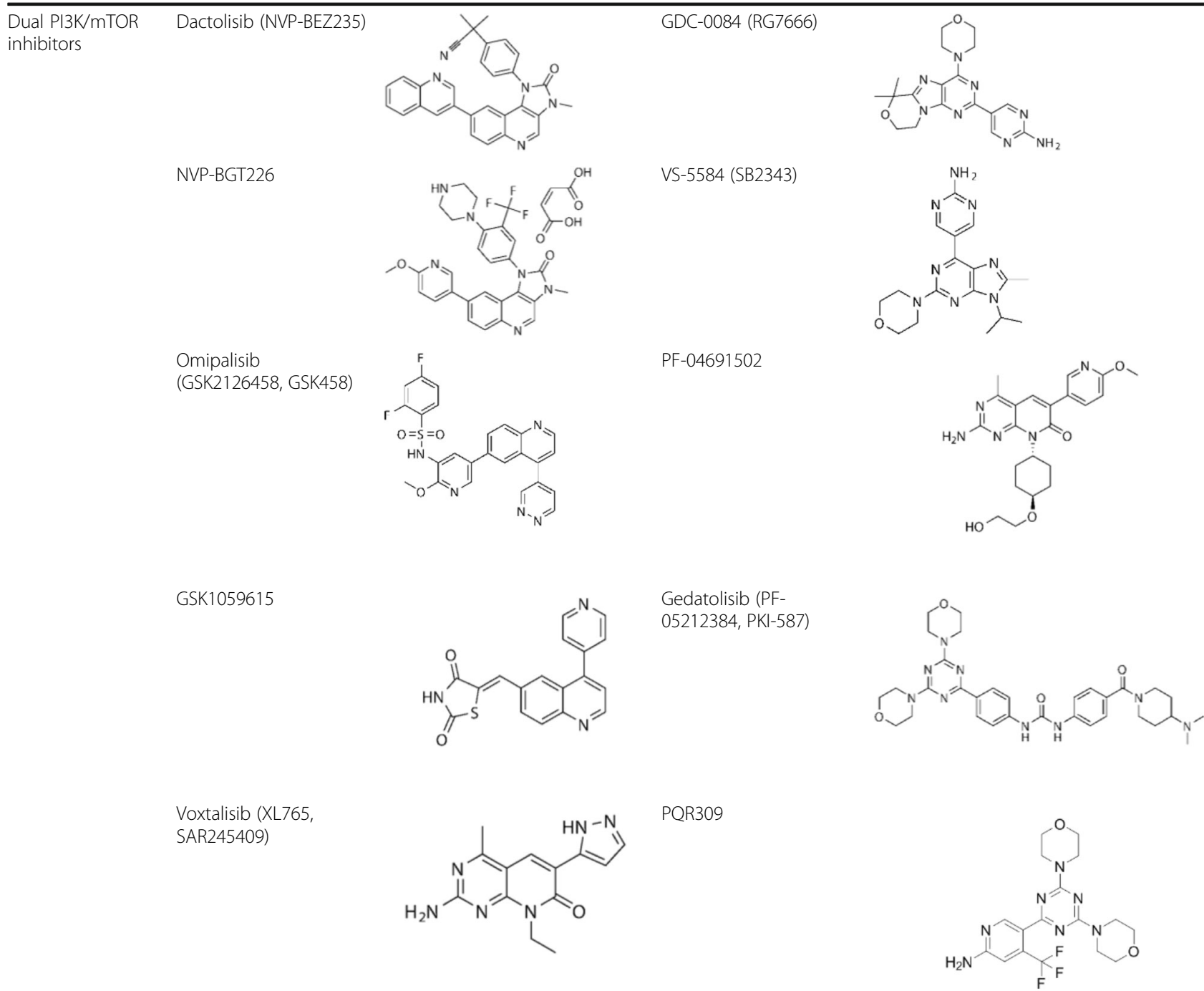

Apitolisib (GDC-0980)

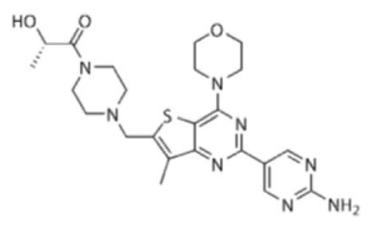

xenograft, without obvious adverse effects [36, 39]. Currently, BKM120 is the most frequently-used PI3K inhibitor in the clinical trials for GBM treatment, since it is well-tolerated and permeable to the blood-brain barrier (BBB). In a phase II study of BKM120 in recurrent GBM, patients with radiologic progression and activation of PI3K/Akt pathway including PIK3CA mutations, PTEN loss and increased phosphorylation of Akt were recruited (NCT01339052). Mild treatment-related toxicities including increased asymptomatic lipase and alanine aminotransferase (ALT)/aspartate transaminase (AST), rash, hyperglycemia and fatigue were seen. Paradoxically, patients harboring PTEN loss and/or PIK3CA mutations were not sensitive to BKM120 treatment even though it inhibits Akt phosphorylation [40]. Phase I and II multicenter studies on the combination of BKM120 and bevacizumab in patients with relapsed/refractory GBM are ongoing. Generally, this combination treatment was welltolerated with mild toxicities such as fatigue, hyperglycemia and ALT elevation. Appropriately $26.5 \%$ of patients 
Table 3 Current status of PI3K inhibitors in clinical trials (data from http://clinicaltrials.gov)

\begin{tabular}{|c|c|c|c|}
\hline Classification & Drug name & Tumor(s) & Clinical trials \\
\hline \multirow[t]{7}{*}{ Pan-PI3K inhibitors } & Pictilisib (GDC-0941) & Breast cancer, NSCLC, NHL, GBM & Phase $\mid / \|$ \\
\hline & Taselisib (GDC-0032) & $\begin{array}{l}\text { Breast, ovarian, uterus and squamous cell lung cancers, } \\
\text { NSCLC, NHL, lymphoma }\end{array}$ & Phase I-III \\
\hline & Buparlisib (BKM120) & $\begin{array}{l}\text { Breast, prostate, endometrial, cervical, esophageal, ovarian, } \\
\text { colorectal, and H\&N cancers, GBM, NSCLC, GIST, RCC, } \\
\text { melanoma, lymphoma, leukemia, }\end{array}$ & Phase $|-|||$ \\
\hline & Pilaralisib (XL147, SAR245408) & $\begin{array}{l}\text { Breast, endometrial, and ovarian cancers, GBM, NSCLC, } \\
\text { lymphoma }\end{array}$ & Phase $\mid / \|$ \\
\hline & Copanlisib (BAY 80-6946) & $\begin{array}{l}\text { Endometrial, and H\&N cancers, cholangiocarcinoma, } \\
\text { lymphoma, NHL }\end{array}$ & Phase I-III \\
\hline & Sonolisib (PX-866) & Prostate, colorectal, and H\&N cancers, melanoma, NSCLC, GBM & Phase $\mid / \|$ \\
\hline & ZSTK474 & Solid tumors & Phase I \\
\hline \multirow[t]{5}{*}{ Isoform-selective inhibitors } & Alpelisib (BYL719) & $\begin{array}{l}\text { Breast, ovarian, gastric, pancreatic, colorectal, H\&N, and } \\
\text { rectal cancers, melanoma, ESCC, NSCLC, RCC, GIST, MM }\end{array}$ & Phase $\mid / \|$ \\
\hline & Idelalisib (CAL-101, GS-1101) & $\mathrm{CLL}, \mathrm{AML}, \mathrm{NHL}, \mathrm{MM}$, and other hematologic malignancies & Phase I-IV \\
\hline & AMG319 & H\&N cancer, CLL, lymphoma & Phase $|/| \mid$ \\
\hline & CH5132799 & Solid tumors & Phase I \\
\hline & MLN1117 (INK1117) & RCC, solid tumors & Phase $\mid / \|$ \\
\hline \multirow[t]{11}{*}{ Dual PI3K/mTOR inhibitors } & Dactolisib (NVP-BEZ235) & $\begin{array}{l}\text { Breast, prostate, and endometrial cancer, pancreatic } \\
\text { neuroendocrine tumor, RCC, GBM, leukemia }\end{array}$ & Phase $\mid / \|$ \\
\hline & NVP-BGT226 & Breast cancer, solid tumors & Phase $\mid / \|$ \\
\hline & Omipalisib (GSK2126458, GSK458) & Solid tumors & Phase I \\
\hline & GSK1059615 & Lymphoma, solid tumors & Phase I \\
\hline & Voxtalisib (XL765, SAR245409) & Breast, and ovarian cancers, NSCLC, lymphoma, GBM & Phase $|/| \mid$ \\
\hline & Apitolisib (GDC-0980) & Breast, prostate, and endometrial cancers, $\mathrm{RCC}, \mathrm{NHL}$ & Phase $\mid / / I$ \\
\hline & GDC-0084 (RG7666) & High-grade gliomas & Phase I \\
\hline & VS-5584 (SB2343) & $\begin{array}{l}\text { Malignant mesothelioma, lymphoma, advanced } \\
\text { non-hematologic malignancies }\end{array}$ & Phase I \\
\hline & PF-04691502 & Breast, and endometrial cancers & Phase $\mid / / I$ \\
\hline & Gedatolisib (PF-05212384, PKI-587) & $\begin{array}{l}\text { Breast, endometrial, colorectal, ovarian, and H\&N cancers, } \\
\text { NSCLC, SCLC, AML }\end{array}$ & Phase $\mid / \|$ \\
\hline & PQR309 & Breast cancer, GBM, lymphoma & Phase $\mid / / 1$ \\
\hline
\end{tabular}

NHL Non-Hodgkin's lymphoma, CLL chronic lymphocytic leukemia, AML acute myeloid leukemia, MM multiple myeloma, NSCLC non-small cell lung cancer, SCLC small cell lung cancer, GBM glioblastoma, GIST gastrointestinal stromal tumor, H\&N head and neck cancer, $R C C$ renal cell cancer, ESCC esophageal squamous cell carcinoma

(18 of 68) had stable disease. Median progression-free survival (PFS) and overall survival (OS) were 5.3 and 10.8 months, respectively. Overall response ratio (RR) was $32.3 \%$ (22 of 68), including 2 complete remission (CR) and 20 partial remission (PR) (NCT01349660) [41, 42]. There are 4 ongoing or completed clinical trials of BKM120 combined with other drugs in patients with newly diagnosed or recurrent GBM. In a phase Ib dose escalation study, BKM120 was combined with LDE225, a Smoothened (Smo) antagonist, in the patients with advanced solid tumors including recurrent GBM (NCT01576666). Combination of BKM120 and Capmatinib (INC280), a c-Met inhibitor, is investigated in a phase Ib/II clinical trials to assess its safety, dose and anti-tumor activity in patients with recurrent GBM with PTEN loss or MET alteration
(NCT01870726). Another phase I study will evaluate the safety and dose of BKM120 in patients with newly diagnosed GBM when given in combination with radiotherapy and temozolomide (NCT01473901). Last but not least, a multi-center phase Ib/II study in patients with recurrent GBM is ongoing to determine the maximum tolerated dose (MTD) and therapeutic effect of BKM120 combined with carboplatin or lomustine (NCT01934361).

\section{XL147}

Pilaralisib (XL147, SAR245408) is an orally bioavailable and reversible pan-class $\mathrm{I}_{\mathrm{A}} \mathrm{PI} 3 \mathrm{~K}$ inhibitor against $\mathrm{p} 110 \alpha / \delta / \gamma$ with $\mathrm{IC}_{50}$ of approximate $30 \mathrm{nM}$, but less potent upon p110 $\beta$ [43]. Apart from GBM, it exhibits dose-dependent anti-proliferative effects on breast cancer 
cells through inhibition on PI3K and Akt activation [44]. XL147 could induce an upregulation of HER3 expression and phosphorylation in HER2-overexpressing breast cancer cells, and it synergizes with trastuzumab or lapatinib to suppress xenograft growth [44, 45]. Currently, XL147 has entered phase I/II clinical trials in a variety of cancers including breast, endometrial, lymphoma and GBM [46-49]. A phase I exploratory pharmacodynamic study using XL147 and XL765 (Voxtalisib, a dual PI3K/mTOR inhibitor) was performed in patients with recurrent GBM prior to surgical resection (NCT01240460). Three cohorts of 21 patients were treated with different doses of XL147 and XL765 for $>10$ days, respectively. The mean tumor to plasma ratios of XL147 and XL765 were from 0.27 to 0.40 , and treatment of these two drugs led to reduced S6 K1 phosphorylation and Ki67 expression, suggesting that they possess a moderate BBB-penetration capacity and a potential to inhibit GBM growth [49].

\section{PX-866}

Sonolisib (PX-866) is an irreversible wortmannin analogue with a short half-life of $18.4 \mathrm{~min}$ in mouse, but showing a more persistent inhibitory effect on PI3K than wortmannin [50, 51]. It exhibits potent inhibition on A549 non-small cell lung cancer (NSCLC) cell xenograft growth, and overcomes the resistance of xenograft to EGFR inhibitor gefitinib [52]. Preclinical studies show that PX-866-induced toxicities include hyperglycemia and increased neutrophils, which could be reversed by the PPAR $\gamma$ agonist pioglitazone without affecting the anti-tumor activity of PX-866 [52, 53]. In 13 human cancer cell line-derived xenografts, tumors with PTEN loss or PIK3CA mutations are sensitive to PX-866, whereas those harboring RAS-activating mutation show resistance, suggesting that $R A S$ mutation may be an important prognostic predictor of PX-866 for cancer treatment [54]. Recent studies using PX-866 alone or in combination with other drugs demonstrates pro-autophagic, anti-invasive and anti-angiogenic activities in GBM cell lines, as well as anti-tumor activities in intracranial GBM xenograft mice $[55,56]$. PX-866 reduced GBM cell number in G1 phase via suppressing cyclin D1 expression and $\mathrm{Rb} 1$ activation, and induced autophagy through promoting the conversion of LC3-I to LC3-II. In addition, it induced a decrease of invasion rate and VEGF secretion in a panel of GBM cell lines. The growth of intracranial U-87 MG glioblastoma xenograft was inhibited leading to longer survival of mice [55]. Furthermore, combination of PX866 and the dinuclear platinum compound BBR3610 displayed synergistic effects on reduction of GBM cell migration and extension of GBM xenograft mice survival [56]. As an orally bioavailable pan-PI3K inhibitor, PX-866 has entered into clinical trials for many cancers including ovarian, colorectal, prostate, head and neck $(\mathrm{H} \& \mathrm{~N})$ cancers, melanoma, NSCLC and GBM [57-62].
In a phase II study, 33 patients with recurrent GBM were orally administrated with PX-866. It was relatively well-tolerated but the overall RR was low. All participants had ceased therapy due to disease progression or toxicities including diarrhea, venous thromboembolism, fatigue, nausea, vomiting, and lymphopenia. 72.7\% (24 of 33) of participants underwent disease progression, while $3.03 \%$ ( 1 of 33 ) of patients had partial response and $24.2 \%$ ( 8 of 33 ) of those achieved stable diseases. The median 6 -month PFS was $17 \%$. It is noteworthy that there was no significant association between clinical outcome and mutations of PTEN, PIK3CA, PIK3R1, or EGFRvIII [62].

\section{GDC-0941}

Pictilisib (GDC-0941) is a derivative of the dual PI3K/ mTOR inhibitor PI-103, but shows inhibition of class I PI3K with less potency to mTOR. It exhibits a comparable anti-proliferative activity to PI-103 against a panel of human cancer cell lines including U-87 MG GBM cells [63]. Furthermore, the oral bioavailability of GDC-0941 is up to $78 \%$ and it shows sustained and remarkable inhibition of Akt phosphorylation and tumor growth (98\% inhibition) in subcutaneous U-87 MG xenograft mice [63]. Combination of GDC-0941 and a Bcl-2 family inhibitor ATB-263 displayed synergistic effects on loss of mitochondrial membrane potential, induction of GBM cell apoptosis and suppressing sphere formation in GBM stem-like cells, via decreasing Akt phosphorylation and Mcl-1 expression [64]. In addition, GDC-0941 also synergizes with a natural compound B10, a glycosylated derivative of betulinic acid, to inhibit GBM cell viability, enhance lysosomal compartments and induce lysosomal membrane permeabilization through increasing TFEB and LAMP1 expression [65]. GDC-0941 and another PI3K inhibitor GNE-317 were used in a preclinical study to investigate their $\mathrm{BBB}$ penetration properties and cerebral distribution in U-87 MG and GS2 intracranial GBM xenograft models. GNE-317 displayed superior BBB penetration in both U-87 MG and GS2 GBM models. In contrast, GDC-0941 barely penetrated through the intact $\mathrm{BBB}$, leading to a higher level of GDC-0941 distribution in the core of U-87 MG tumor than in the healthy part of the brain [66]. This result suggests that it may be difficult for GDC-0941 to reach the distant part of GBM, thus being insufficient to treat GBM with intact BBB. An in-vivo study also shows that combination of GDC-0941, irinotecan, sunitinib and temozolomide doesn't significantly prolong the survival of mice with GBM xenograft, possibly due to the poor BBB permeability of GDC-0941 [67]. Nevertheless, a phase IIb clinical trial in patients with recurrent GBM is ongoing to evaluate the anti-tumor activity of pembrolizumab (MK-3475, a PD-1 monoclonal antibody) alone or in combination of PI3K/Akt 
inhibitors including GDC-0941, NVP-BEZ235 and GDC-0068 (NCT02430363).

\section{Other novel pan-PI3K inhibitors}

ZSTK474, AMG 511, GDC-0032 and BAY 80-6946 are more potent inhibitors against PI3K, and may be attractive options for GBM treatment. Both ZSTK474 and AMG 511 could suppress the proliferation of GBM cell lines and subcutaneous U-87 MG xenograft growth [68-70]. GDC-0032 exhibits potent anti-proliferative and antitumor activities in head and neck squamous cell carcinoma and uterine serous carcinomas cell lines and xenografts with PIK3CA mutations or amplifications [71, 72]. BAY 80-6946, a more potent inhibitor against $\mathrm{p} 110 \alpha$ and $\mathrm{p} 110 \delta$, impedes cell proliferation and induces apoptosis in human breast, endometrial and hematologic cancer cell lines with PIK3CA mutations and/or HER2 overexpression [73]. Moreover, significant tumor regression was observed in animals bearing HER2-amplified and PIK3CA-mutated breast, colon or NSCLC tumors treated with BAY 80-6946 $[73,74]$. Although there is no clinical trial of these inhibitors for GBM treatment yet, ZSTK474, GDC-0032 and BAY 80-6946 are currently in phase I-III trials in patients with advanced solid tumors and hematologic malignancies.

\section{Isoform-selective PI3K inhibitors}

Selective inhibitors against p110 isoforms may display less off-target effects and toxicities, therefore, are alternative options for GBM treatment. In-vitro studies using traditional isoform-selective PI3K inhibitors show that class $\mathrm{I}_{\mathrm{A}}$ PI3K isoforms play distinct roles in glioma progression. Inhibition of $\mathrm{p} 110 \alpha$ by PIK-75 or A66 is sufficient to suppress GBM cell viability, migration and invasion, whereas inhibition of $\mathrm{p} 110 \beta$ by TGX-221 only blocks cell migration, and inhibition of $\mathrm{p} 110 \delta$ by IC 87114 or CAL-101 moderately impedes cell proliferation and migration $[19,23]$. Taken together, due to the predominant role of $\mathrm{p} 110 \alpha$ in RTK-mediated Akt signaling, inhibition of $\mathrm{p} 110 \alpha$ may be an effective treatment for GBM.

Since PIK3CA mutations and PTEN loss/mutation are frequently found in GBM, isoform-selective PI3K inhibitors, especially against $\mathrm{p} 110 \alpha$ and $\mathrm{p} 110 \beta$, may have potentials for the treatment of GBM bearing these genetic mutations. Currently, several novel isoformselective PI3K inhibitors including BYL719, MLN1117, CAL-101, GSK2636771 and CH5132799 have entered phase I/II clinical trials in patients with solid tumors and hematologic malignancies. However, no clinical trial of isoform-selective PI3K inhibitors has been carried out on GBM patients (Table 3).

Alpelisib (BYL719) is an orally available p110 $\alpha$ inhibitor against with $\mathrm{IC}_{50}$ of $5 \mathrm{nM}$ and a half-life of $2.9 \mathrm{~h}$ in rat [75]. It exhibits potent anti-proliferative and antitumor activities in a variety of cancers including breast cancer, nasopharyngeal carcinoma and lung squamous cell carcinoma (LSCC) in a PIK3CA-dependent manner [76-78]. It suppresses spheroid growth, invasion and epithelial-to-mesenchymal transition (EMT) in PIK3CAmutated LSCC cells, and reduces tumor growth and mesenchymal phenotype in xenograft mice [78]. Cancer cells carrying PIK3CA mutations are more sensitive to BYL719, while tumors bearing PIK3CA amplifications or PTEN mutations only respond moderately. Thus, it suggests that PIK3CA alteration may be a positive prognostic predictor for the clinical use of p110 $\alpha$-selective inhibitors [79]. BYL719 is currently in phase I/II trials in patients with breast cancer, lung cancer, pancreatic cancer and squamous cell carcinoma etc. Another p110 $\alpha$ selective inhibitor MLN1117, and a $\mathrm{p} 110 \alpha / \gamma$ inhibitor CH5132799 are also in phase I/II trials for advanced solid malignancies treatment [80, 81].

The selective p110 $\beta$ inhibitor GSK2636771 has entered into phase I/II trials for the treatment of advance solid tumors bearing PTEN loss or mutation (NCT01458067) [82]. Due to the high expression levels of $\mathrm{p} 110 \delta$ and p110 $\gamma$ in leukocytes, the p110 $\delta$ inhibitors CAL-101 and AMG319, as well as the $\mathrm{p} 110 \delta / \gamma$ inhibitor INK1197 are currently in phase I/II clinical trials for patients with hematologic malignancies including leukemia, lymphoma and myeloma.

\section{Dual PI3K/mTOR inhibitors}

Although mTOR plays important roles in regulating cancer cell growth, metabolism and protein synthesis, the allosteric mTOR inhibitor rapamycin (sirolimus) fails to be approved as an anti-cancer agent due to its immunosuppresive effects [83]. Subsequently, its structural analogues (rapalogs) such as RAD001 (everolimus) and CCI-779 (temsirolimus) with reduced immunosuppresive effects and improved pharmacological properties are designed and have been approved by FDA for the treatment of subependymal giant cell astrocytoma (SEGA) or renal cell carcinoma, suggesting a potential of mTOR inhibitors in cancer treatment $[84,85]$. However, shortterm treatment of rapamycin and its analogues inhibits mTORC1 activity and triggers a negative feedback loop to augment Akt activation (Fig. 1) [86, 87]. In addition, cancer cells still maintain mTOR activation even though the activities of PI3K and Akt are suppressed [88]. These crosstalk and feedback between mTOR and PI3K largely limit the therapeutic effects of mTOR or PI3K inhibitors. Therefore, dual PI3K/mTOR inhibitors such as NVP-BEZ235, XL765, GDC-0084 and PQR309 are produced and currently tested in clinical trials (Table 3). 


\section{NVP-BEZ235}

Dactolisib (NVP-BEZ235) is an orally bioavailable, reversible, ATP-competitive dual PI3K and mTORC1/2 inhibitor, which has been widely used in preclinical studies on various cancers including GBM, breast, colorectal and lung cancers [89-92]. It sensitizes GBM cells to temozolomide and radiotherapy in vitro and in vivo through reducing Akt activation, elevating pro-apoptotic molecules Bax and caspase-3 expression, and blocking radiation-induced DNA damage repair $[89,93]$. However, it is important to note that its inhibitory effect on Akt activation is reversible, thus, enhanced radiosensitization is only observed when U-87 MG cells are simultaneously treated with NVP-BEZ235 and ionizing radiation [94]. Furthermore, NVP-BEZ235 alone or in combination of MEK1/2 inhibitors UO126 or SL327 promotes cell differentiation to neuronal and glial lineages and suppresses the tumorigenic potential of GBM stem-like cells (GSLCs) $[95,96]$. These findings indicate that NVP-BEZ235 plus temozolomide, radiotherapy or other inhibitors may be possible strategies for GBM treatment. NVP-BEZ235 has already entered phase I/II clinical trials in a number of cancers including pancreatic neuroendocrine tumor, breast cancer, prostate cancer and leukemia [97-99]. In a phase I dose-escalation study of patients with advanced solid tumors, NVP-BEZ235 was generally well-tolerated with mild dose-limiting toxicities (DLTs) including mucositis, hyperglycemia, dehydration, fatigue and thrombocytopenia [98]. A phase Ib study in patients with advanced solid tumors including GBM showed that combination of NVP-BEZ235 and everolimus exhibited limited efficacy and intolerable toxicities including fatigue, diarrhea, nausea, mucositis, and elevated liver enzymes [99]. NVP-BEZ235 is also being applied in combination with MK-3475 in GBM patients in a phase IIB clinical trial mentioned above (NCT02430363).

\section{XL765}

Voxtalisib (XL765, SAR245409) is also a potent ATPcompetitive, orally bioavailable, BBB-permeable PI3K/ mTOR inhibitor with high inhibition on $\mathrm{p} 110 \gamma$ and an additional inhibition against DNA protein kinase [100]. It exhibits robust anti-proliferative activity in a panel of GBM cell lines including U-87 MG, U-251 MG and U373 MG via decreased phosphorylation of Akt, GSK3 $\beta$ and p70S6 K, reduced expression of cyclin D, and G1cycle arrest. Distinct inhibitory effects of XL765 on cell proliferation are noted toward cancer cells bearing diverse genetic alterations. Cell lines harboring PIK3CA mutations or amplifications but without $R A S$ mutations are most sensitive to XL765, whereas cells with $R A S \mathrm{mu}$ tations are relative insensitive to XL765 even if they have PIK3CA mutations. Furthermore, XL765 alone or in combination of temozolomide markedly suppresses growth of subcutaneous or intracranial GBM xenograft, and prolongs survival of tumor-bearing nude mice, indicating its potent anti-GBM activity and $\mathrm{BBB}$ penetration capacity $[100,101]$. In a phase I safety and dose-escalation study, drug-related toxicities of XL765 are tolerable in patients with solid tumors. They included nausea, diarrhea, vomiting, decreased appetite plus increased ALT/AST [102]. A phase I dose-escalation study in high-grade glioma patients using combination of XL765 with temozolomide, with or without concurrent radiotherapy, showed similar treatment-related adverse effects plus thrombocytopenia [103]. The BBB penetration capacity of XL765 was demonstrated in another phase I study in patients with recurrent GBM. S6 K1 phosphorylation and Ki67 expression were also reduced by XL765 (NCT01240460) [49].

\section{GDC-0084}

GDC-0084 (RG7666) is a novel BBB-penetrating PI3K/ mTOR inhibitor displaying a high brain-to-plasma ratio (1.9-3.3). It remarkably impedes the proliferation of five GBM cell lines and suppresses the growth of U-87 MG GBM xenografts through decreasing Akt phosphorylation [104]. In patients with progressive or recurrent high-grade glioma, the most frequent adverse events were fatigue, hyperglycemia, nausea, hypertriglyceridemia, rash, hypophosphatemia, decreased appetite, diarrhea, and stomatitis. High brain-to-plasma ratio and tumor-to-plasma ratio of GDC-0084 also suggested a uniform distribution throughout the brain (NCT01547546) [105].

\section{PQR309}

PQR309 is a novel, ATP-competitive, BBB-penetrating pan-PI3K/mTOR inhibitor with potent inhibitory effects on Akt and ribosomal protein S6 phosphorylation. In a PC-3 prostate tumor xenograft model, PQR309 has been shown to be oral bioavailable, and it effectively inhibits PI3K/Akt signaling and reduces tumor growth [106]. Phase I studies of PQR309 in patients with advanced solid tumors show that and the most frequent adverse events are fatigue, hyperglycemia, nausea, diarrhea, constipation, rash, anorexia and vomiting. Concentrationdependent hyperglycemia has been confirmed as a mechanism-based toxicity of PQR309 (NCT01940133, NCT02483858) [107, 108]. A non-randomized phase II study in patients with progressive GBM is ongoing to evaluate the safety, efficacy, pharmacokinetics and pharmacodynamic effects of PQR309 (NCT02850744).

Other novel dual PI3K/mTOR inhibitors including NVP-BGT226, GSK2126458, GSK1059615, GDC-0980, VS-5584, PF-04691502 and PKI-587 have entered phase I/II clinical trials for advanced solid tumors. However, no clinical study on these inhibitors has been carried out in patients with GBM. 


\section{Combination of $\mathrm{PI} 3 \mathrm{~K}$ and other molecules' inhibitors}

Considering that inhibition of PI3K isoforms might lead to compensatory activation of other signaling pathways, or the feedback, and subsequent compromise of the inhibitory effects, GBM patients may benefit from combination treatment strategies by dual inhibition of PI3K and other molecules.

Activation of RTKs not only drives PI3K/Akt signaling activation, but also stimulates other signaling pathways including MAPK, NF- $\mathrm{BB}$ and STAT3. It is noteworthy that, PIK3CA and EGFRvIII mutations often lead to PI3K activation independent of RTKs such as EGFR, HER2, PDGFR, VEGFR and c-Met, suggesting that inhibition of RTKs alone is not sufficient to obstruct PI3K/Akt signaling. Evidence shows that overall alteration (including amplification, mutation, rearrangement and altered splicing) of EGFR in TCGA GBM samples is up to $57.4 \%$ [4]. Therefore, PI3K inhibitors may need to work with the inhibitors or monoclonal antibodies of RTKs for cancer treatment. Preclinical studies show that combined inhibition of PI3K and EGFR displays synergism in breast cancer in vitro and in vivo, leading to retarded cell growth and tumor regression [109, 110]. Compared with single inhibitor alone, combination of a dual PI3K/ mTOR inhibitor PF-05212384 and a pan-ERBB inhibitor PF-00299804 (dacomitinib) induces more apoptosis of GBM cells harboring both EGFR amplification and PI3K activation [111]. Currently, combination of PI3K inhibitors and RTKs inhibitors has become a therapeutic strategy for cancer treatment in clinical studies. A phase Ib study of BKM120 and trastuzumab (a HER2 antibody) in patients with $H E R 2^{+}$or trastuzumab-resistant breast cancer demonstrates that this combination is generally well-tolerated and it inhibits activation of both PI3K/Akt and ERK pathways [112]. In a phase I dose-escalation study in patients with solid tumors, safety and efficacy of XL147 plus an EGFR monoclonal antibody erlotinib were evaluated. The combination exhibited limited antitumor activity and similar toxicities as with XL147 alone [113]. With respect to GBM patients, a phase Ib/II study of BKM120 plus a c-Met inhibitor INC280 in patients with recurrent GBM bearing PTEN loss or MET alteration is still ongoing (NCT01870726).

PI3K/Akt and MAPK pathways interact with each other to build a signaling network including convergence, crosstalk, and feedback loops. Ras is capable of interacting with the catalytic isoforms of PI3K to activate PI3K/Akt pathway, while it also serves as a small G-protein to activate MAPK pathway [114]. Therefore, combination therapies targeting PI3K/Akt and MAPK pathways may have synergism in cancers harboring $R A S$ mutations. Evidence shows that mice with $K-R A S$ mutated lung cancer well respond to the combination of NVP-BEZ235 and a MEK inhibitor ARRY-142886, rather than NVP-BEZ235 alone [115].
Moreover, combination of BKM120 and MEK inhibitors exhibits decreased glioblastoma cell viability and prolonged survival of mice with intracranial xenograft, through downregulating the phosphorylation of ERK, Akt and p70S6 K [116]. Combination of NVP-BEZ235 and MEK1/2 inhibitors UO126 or SL327 displays synergistic inhibitory effect on self-renewal and tumorigenic capacities of GBM stem-like cells (GSLCs), and prolongs the survival of mice with GSLC xenograft [96]. In addition, PI3K/ Akt and MKK4/JNK pathways also co-operate to regulate cancer cell survival, migration and invasion [117]. Our previous study showed that concurrent inhibition of PI3K $\beta$ and JNK synergistically suppresses GBM cell proliferation and migration, and tumor growth in U-87 MG xenograft mice [19]. A phase I trial shows that patients with advanced solid tumors receiving combination therapies targeting PI3K/Akt and Ras/Raf/MEK/ERK pathways have better prognosis in response to PTEN deletions and KRAS/BRAF mutations [118]. BKM120 in combination with the MEK1/2 inhibitor trametinib (GSK1120212) produced clinical benefits to patients with $K R A S$-mutant ovarian cancer [119].

Accumulating evidence supports that combined inhibition of PI3K and Hedgehog (Hh) pathways' molecules such as Smoothened (Smo) is superior to single agent alone [120, 121]. Activation of PI3K/Akt signaling is accompanied by sonic hedgehog (Shh) signaling activation in PTEN-deficient GBM cells [120]. Growth factorinduced activation of $\mathrm{Hh}$ signaling positively correlates with Akt phosphorylation level in esophageal cancer and breast cancer, while inhibition of PI3K activity decreases Smo and Gli1 expression, suggesting that Hh signaling activation may be partially activated through PI3K/Akt signaling [122, 123]. In addition, loss of PTEN confers medulloblastoma cells resistance to Hh pathway inhibitor GDC-0449 [124]. These findings indicate that there is a crosstalk between PI3K/Akt and Hh pathways, and combined inhibition of these pathways may have synergistic outcomes. Evidence shows that combination of BKM120 and a Smo inhibitor LDE225 significantly reduces tumor growth and increases apoptosis in intracranial GBM xenografts [120]. This combination treatment in patients with advanced solid tumors including recurrent GBM is generally tolerable with mild adverse events such as increased ALT/AST, blood creatine phosphokinase and alkaline phosphatase, hyperglycemia, aphasia, nausea and fatigue (NCT01576666) [125]. In addition, combination of NVPBEZ235 and LDE225 also shows synergistic inhibitory effects on self-renewal capacity of pancreatic cancer stem cells (CSCs) and their growth in nude mice [121].

\section{Clinical implications}

To date, huge breakthroughs in understanding the central role of PI3K signaling in cancer have been achieved, 
suggesting an effective therapeutic approach for GBM via targeting PI3K. However, only a small number of PI3K inhibitors could step into clinical trials for GBM treatment, showing their limited effects on tumor regression at tolerated doses. Activation of compensatory pathways, drug toxicity and blood-brain barrier have posed challenges to further development of PI3K inhibitors in clinical trials. Firstly, blockade of a single pathway generally gives rise to the compensatory activation of other pathways to relieve the inhibitory effects and maintain tumor cell survival [126]. Although PI3K/Akt signaling plays an essential role in the survival and motility of tumor cells, GBM cells are not completely addictive to this signaling pathway. Moreover, another challenge is to translate the preclinical findings to clinical activity and improve the therapeutic effects of PI3K inhibitors at acceptable tolerability in GBM patients. Although pharmacological inhibition of PI3K suppresses GBM tumor growth and demonstrates favorable outcomes in in-vitro experimental and in-vivo preclinical studies, the clinical data show that their therapeutic effects on GBM patients do not reach the expectations, mostly with stable diseases [40, 42, 62, 103]. Indeed, high doses or long-period treatment of PI3K inhibitors may not be tolerated in GBM patients due to their on-target or off-target toxicities, leading to the low expectations at acceptable doses. The majority of PI3K inhibitors in the clinical studies exhibit adverse effects including fatigue, hyperglycemia, nausea, vomiting and increased ALT/AST [62, $102,105]$. In addition, the efficacy of PI3K inhibitors on GBM patients is largely limited by BBB, which is heterogeneously disrupted in GBM areas [127]. BBB integrity is completely compromised in the central regions of GBM, whereas it is slightly undermined in the peripheral areas with more invasive properties [128]. This intact BBB could prevent drugs delivering to invasive GBM cells, leading to cell survival and tumor recurrence. Therefore, rational combination with other molecule's inhibitors or other therapeutic approaches, and discovery of more specific PI3K inhibitors or an effective drug-delivery system with $\mathrm{BBB}$ permeability are required to improve the therapeutic effects of PI3K inhibitors for GBM.

Current clinical trials on GBM patients tend to use pan-PI3K and dual PI3K/mTOR inhibitors rather than isoform-selective PI3K inhibitors. Although the latter shows less off-target effects and toxicities, their clinical efficacy and application are largely limited by various genetic alterations such as PIK3CA, RAS and PTEN mutations, seen in patients. In order to maximize the applications of these specific inhibitors, future therapeutic strategies should include the molecular pathological diagnosis of GBM patients like PIK3CA, RAS mutations and PTEN loss/mutation prior to drug administration.

\section{Conclusions}

Targeting PI3K signaling as a therapeutic approach for cancer treatment has been discussed for more than a decade based on a solid foundation of experimental and preclinical studies. Recently, the p110 $\delta$ inhibitor CAL-101 has been approved by FDA for certain types of lymphoma, offering hopes of PI3K inhibitors for cancer treatment [129]. Due to many challenges, clinical data do not favor PI3K inhibitors in GBM treatment, suggesting that targeting PI3K alone is not sufficient to treat GBM.

The future strategies to promote the potential of PI3K inhibitors for GBM treatment need to focus upon: [1] identifying genetic alternations such as PI3KCA mutations, PTEN mutations/loss and RAS mutations prior to the treatment regime; [2] rational combinations with other molecules' inhibitors or other therapies, on the basis of understanding of the crosstalks between PI3K and other signaling molecules/pathways; [3] employing a BBB-permeable drug delivering system specifically targeting GBM cells to decrease toxicities on normal cells. Implement of these ideas may guide us in the right directions and develop more effective therapeutic approaches for GBM treatment.

\section{Abbreviations \\ 4EBP: Eukaryotic initiation factor 4E-binding protein; ALT: Alanine aminotransferase; AST: Aspartate transaminase; BBB: Blood-brain barrier; CR: Complete remission; CSC: Cancer stem cell; DLT: Dose-limiting toxicity; EGFR: Epidermal growth factor receptor; EMT: Epithelial-to-mesenchymal transition; GBM: Glioblastoma multiforme; GPCR: G protein-coupled receptor; GSLC: Glioblastoma stem-like cell; H\&N: Head and neck; HCC: Hepatocellular carcinoma; Hh: Hedgehog; $I_{50}$ : Half maximal inhibitory concentration; LSCC: Lung squamous cell carcinoma; MTD: Maximum tolerated dose; mTOR: Mammalian target of rapamycin; mTORC: mTOR complex; NSCLC: Non-small cell lung cancer; OS: overall survival; PDK-1: Phosphoinositide- dependent kinase 1; PFS: Progression-free survival; PHLPP: PH domain and leucine rich repeat protein phosphatase; PI3K: Phosphatidylinositol 3-kinase; PIP2: Phosphatidylinositol 4,5-bisphosphate; PIP3: Phosphatidylinositol 3,4,5-triphosphate; PR: Partial remission; PTEN: Phosphatase and tensin homolog deleted on chromosome 10; RR: Response ratio; RTK: Receptor tyrosine kinase; Smo: Smoothened; TCGA: The Cancer Genome Atlas; TRAIL: Tumor necrosis factor-related apoptosis inducing ligand; TSC: Tuberous sclerosis complex}

\section{Acknowledgements}

The authors would like to thank Wen-lan Liu, Zong-yang Li, Yuan Zhang and Hui Tan for the discussion of the manuscript.

\section{Funding}

This work was supported by Grants from National Natural Science Foundation of China (No. 81602195), China Postdoctoral Science Foundation (No. 2016M592588), Shenzhen Science and Technology Innovation Commission (No. JCYJ20160425104157183, No. ZDSYS20140509173142601, and No. GCZX2015050411225563), the Open Funds of State Key Laboratory of Oncology in South China (No. HN2016-09), and the Fund of High Level Medical Discipline Construction in Shenzhen (No. 2016031638).

Availability of data and materials Not applicable. 


\section{Authors' contributions}

HFZ is the major contributor in writing the manuscript. JW, WS, CPW and ZPC provided suggestions to revise the manuscript. SSTT and WPL designed and revised the manuscript. All authors have reviewed the final manuscript.

\section{Competing interests}

No competing of interest exits in the submission of this manuscript, and it has been approved by all authors for publication.

\section{Consent for publication}

Not applicable.

\section{Ethics approval and consent to participate}

Not applicable.

\section{Publisher's Note}

Springer Nature remains neutral with regard to jurisdictional claims in published maps and institutional affiliations.

\section{Author details}

'Department of Neurosurgery \& Shenzhen Key Laboratory of Neurosurgery, the First Affiliated Hospital of Shenzhen University, Shenzhen Second People's Hospital, Shenzhen 518035, China. 'Department of Neurosurgery/ Neuro-oncology, Sun Yat-sen University Cancer Center, State Key Laboratory of Oncology in South China, Collaborative Innovation Center for Cancer Medicine, Guangzhou 510060, China. ${ }^{3}$ Department of Health Technology and Informatics, The Hong Kong Polytechnic University, Hong Kong, China. ${ }^{4}$ College of Clinical Medicine, Anhui Medical University, Hefei 230032, China.

\section{Received: 25 January 2017 Accepted: 26 May 2017}

\section{Published online: 07 June 2017}

\section{References}

1. Dolecek TA, Propp JM, Stroup NE, Kruchko C. CBTRUS statistical report: primary brain and central nervous system tumors diagnosed in the United States in 2005-2009. Neuro-Oncology. 2012;14(Suppl 5):1-49.

2. Schwartzbaum JA, Fisher JL, Aldape KD, Wrensch M. Epidemiology and molecular pathology of glioma. Nat Clin Pract Neurol. 2006;2(9):494-503.

3. Stupp R, Mason WP, van den Bent MJ, Weller M, Fisher B, Taphoorn MJ, et al. Radiotherapy plus concomitant and adjuvant temozolomide for glioblastoma. N Engl J Med. 2005;352(10):987-96.

4. Brennan CW, Verhaak RG, McKenna A, Campos B, Noushmehr H, Salama SR, et al. The somatic genomic landscape of glioblastoma. Cell. 2013;155(2):462-77.

5. Frederick L, Wang XY, Eley G, James CD. Diversity and frequency of epidermal growth factor receptor mutations in human glioblastomas. Cancer Res. 2000;60(5):1383-7.

6. Molina JR, Agarwal NK, Morales FC, Hayashi Y, Aldape KD, Cote G, et al. PTEN, NHERF1 and PHLPP form a tumor suppressor network that is disabled in glioblastoma. Oncogene. 2012;31(10):1264-74.

7. Song MS, Salmena L, Pandolfi PP. The functions and regulation of the PTEN tumour suppressor. Nat Rev Mol Cell Biol. 2012;13(5):283-96.

8. Cantley LC. The phosphoinositide 3-kinase pathway. Science. 2002; 296(5573):1655-7.

9. Nojima H, Tokunaga C, Eguchi S, Oshiro N, Hidayat S, Yoshino K, et al. The mammalian target of rapamycin (mTOR) partner, raptor, binds the mTOR substrates p70 S6 kinase and 4E-BP1 through their TOR signaling (TOS) motif. J Biol Chem. 2003;278(18):15461-4.

10. Guerreiro AS, Fattet S, Fischer B, Shalaby T, Jackson SP, Schoenwaelder SM, et al. Targeting the PI3K p110alpha isoform Inhibits medulloblastoma proliferation, chemoresistance, and migration. Clin Cancer Res. 2008; 14(21):6761-9.

11. Weber GL, Parat MO, Binder ZA, Gallia GL, Riggins GJ. Abrogation of PIK3CA or PIK3R1 reduces proliferation, migration, and invasion in glioblastoma multiforme cells. Oncotarget. 2011;2(11):833-49.

12. Jia S, Liu Z, Zhang S, Liu P, Zhang L, Lee SH, et al. Essential roles of $\mathrm{PI}(3) \mathrm{K}-\mathrm{p} 110 \mathrm{beta}$ in cell growth, metabolism and tumorigenesis. Nature. 2008:454(7205):776-9.

13. Samuels Y, Wang Z, Bardelli A, Silliman N, Ptak J, Szabo S, et al. High frequency of mutations of the PIK3CA gene in human cancers. Science. 2004;304(5670):554.
14. Gallia GL, Rand V, Siu IM, Eberhart CG, James CD, Marie SK, et al. PIK3CA gene mutations in pediatric and adult glioblastoma multiforme. Mol Cancer Res. 2006;4(10):709-14.

15. Hartmann C, Bartels G, Gehlhaar C, Holtkamp N, von Deimling A. PIK3CA mutations in glioblastoma multiforme. Acta Neuropathol. 2005;109(6):639-42.

16. Knobbe CB, Trampe-Kieslich A, Reifenberger G. Genetic alteration and expression of the phosphoinositol-3-kinase/Akt pathway genes PIK3CA and PIKE in human glioblastomas. Neuropathol Appl Neurobiol. 2005;31(5):486-90.

17. Gymnopoulos M, Elsliger MA, Vogt PK. Rare cancer-specific mutations in PIK3CA show gain of function. Proc Natl Acad Sci U S A. 2007;104(13):5569-74.

18. Jamieson S, Flanagan JU, Kolekar S, Buchanan C, Kendall JD, Lee WJ, et al. A drug targeting only p110alpha can block phosphoinositide 3-kinase signalling and tumour growth in certain cell types. Biochem J. 2011;438(1):53-62

19. Zhao HF, Wang J, Jiang HR, Chen ZP, To SS. PI3K p110beta isoform synergizes with JNK in the regulation of glioblastoma cell proliferation and migration through Akt and FAK inhibition. J Exp Clin Cancer Res. 2016;35:78.

20. Holand K, Boller D, Hagel C, Dolski S, Treszl A, Pardo OE, et al. Targeting class IA PI3K isoforms selectively impairs cell growth, survival, and migration in glioblastoma. PLoS One. 2014;9(4):e94132.

21. Carvalho S, Milanezi F, Costa JL, Amendoeira I, Schmitt F. PIKing the right isoform: the emergent role of the p110beta subunit in breast cancer. Virchows Arch. 2010;456(3):235-43.

22. Cui B, Tao J, Yang Y. Studies on the expression patterns of class I PI3K catalytic subunits and its prognostic significance in colorectal cancer. Cell Biochem Biophys. 2012;62(1):47-54.

23. Luk SK, Piekorz RP, Nurnberg B, Tony To SS. The catalytic phosphoinositol 3kinase isoform p110delta is required for glioma cell migration and invasion. Eur J Cancer. 2012:48(1):149-57.

24. Chen $H$, Mei L, Zhou L, Shen $X$, Guo C, Zheng Y, et al. PTEN restoration and PIK3CB knockdown synergistically suppress glioblastoma growth in vitro and in xenografts. J Neuro-Oncol. 2011;104(1):155-67.

25. Utermark T, Rao T, Cheng H, Wang Q, Lee SH, Wang ZC, et al. The p110alpha and p110beta isoforms of PI3K play divergent roles in mammary gland development and tumorigenesis. Genes Dev. 2012;26(14):1573-86.

26. Wee $S$, Wiederschain D, Maira SM, Loo A, Miller C, de Beaumont R, et al. PTEN-deficient cancers depend on PIK3CB. Proc Natl Acad Sci U S A. 2008;105(35):13057-62

27. Herman SE, Johnson AJ. Molecular Pathways: Targeting Phosphoinositide 3-Kinase p110-Delta in Chronic Lymphocytic Leukemia. Clin Cancer Res. 2012:18(15):4013-8

28. Balakrishnan K, Peluso M, Fu M, Rosin NY, Burger JA, Wierda WG, et al. The phosphoinositide-3-kinase (PI3K)-delta and gamma inhibitor, IPI-145 (Duvelisib), overcomes signals from the PI3K/AKT/S6 pathway and promotes apoptosis in CLL. Leukemia. 2015;29(9):1811-22.

29. Boller D, Schramm A, Doepfner KT, Shalaby T, von Bueren AO, Eggert A, et al. Targeting the phosphoinositide 3-kinase isoform p110delta impairs growth and survival in neuroblastoma cells. Clin Cancer Res. 2008:14(4):1172-81.

30. Tzenaki N, Andreou M, Stratigi K, Vergetaki A, Makrigiannakis A, Vanhaesebroeck B, et al. High levels of p110delta PI3K expression in solid tumor cells suppress PTEN activity, generating cellular sensitivity to p110delta inhibitors through PTEN activation. FASEB J. 2012;26(6):2498-508.

31. Monterrubio M, Mellado M, Carrera AC, Rodriguez-Frade JM. PI3Kgamma activation by CXCL12 regulates tumor cell adhesion and invasion. Biochem Biophys Res Commun. 2009;388(2):199-204.

32. Xie Y, Abel PW, Kirui JK, Deng C, Sharma P, Wolff DW, et al. Identification of upregulated phosphoinositide 3-kinase gamma as a target to suppress breast cancer cell migration and invasion. Biochem Pharmacol. 2013:85(10):1454-62.

33. Guerreiro AS, Fattet S, Kulesza DW, Atamer A, Elsing AN, Shalaby T, et al. A sensitized RNA interference screen identifies a novel role for the PI3K p110gamma isoform in medulloblastoma cell proliferation and chemoresistance. Mol Cancer Res. 2011;9(7):925-35.

34. Rodon J, Dienstmann R, Serra V, Tabernero J. Development of PI3K inhibitors: lessons learned from early clinical trials. Nat Rev Clin Oncol. 2013;10(3):143-53.

35. Burger MT, Pecchi S, Wagman A, Ni ZJ, Knapp M, Hendrickson T, et al. Identification of NVP-BKM120 as a Potent, Selective, Orally Bioavailable Class I PI3 Kinase Inhibitor for Treating Cancer. ACS Med Chem Lett. 2011;2(10):774-9.

36. Koul D, Fu J, Shen R, LaFortune TA, Wang S, Tiao N, et al. Antitumor activity of NVP-BKM120-a selective pan class I PI3 kinase inhibitor showed differential forms of cell death based on $\mathrm{p} 53$ status of glioma cells. Clin Cancer Res. 2012;18(1):184-95. 
37. Jane EP, Premkumar DR, Morales A, Foster KA, Pollack IF. Inhibition of phosphatidylinositol 3-kinase/AKT signaling by NVP-BKM120 promotes ABT-737-induced toxicity in a caspase-dependent manner through mitochondrial dysfunction and DNA damage response in established and primary cultured glioblastoma cells. J Pharmacol Exp Ther. 2014;350(1):22-35.

38. Foster KA, Jane EP, Premkumar DR, Morales A, Pollack IF. NVP-BKM120 potentiates apoptosis in tumor necrosis factor-related apoptosis-inducing ligand-resistant glioma cell lines via upregulation of Noxa and death receptor 5. Int J Oncol. 2015;47(2):506-16.

39. Netland IA, Forde HE, Sleire L, Leiss L, Rahman MA, Skeie BS, et al. Treatment with the PI3K inhibitor buparlisib (NVP-BKM120) suppresses the growth of established patient-derived GBM xenografts and prolongs survival in nude rats. J Neuro-Oncol. 2016;

40. Wen PY, Alfred Yung WK, Mellinghoff IK, Ramkissoon S, Alexander BM, Rinne ML, et al. Phase II trial of the phosphatidyinositol-3 kinase (PI3K) inhibitor buparlisib (BKM120) in recurrent glioblastoma [abstract]. J Clin Oncol. 2014:32:2019.

41. Shih KC, Acs P, Burris HA, Hart LL, Kosloff RA, Lamar RE, et al. Phase I study of the combination of BKM120 and bevacizumab in patients with relapsed/ refractory glioblastoma multiforme (GBM) or other refractory solid tumors [abstract]. J Clin Oncol. 2013;31:e13045.

42. Shih KC, Chowdhary SA, Becker KP, Baehring JM, Liggett WH, Burris HA, et al. A phase II study of the combination of BKM120 (buparlisib) and bevacizumab in patients with relapsed/refractory glioblastoma multiforme (GBM) [abstract]. J Clin Oncol. 2015:33:2065.

43. Foster P, Yamaguchi K, Hsu PP, Qian F, Du X, Wu J, et al. The Selective PI3K Inhibitor XL147 (SAR245408) Inhibits Tumor Growth and Survival and Potentiates the Activity of Chemotherapeutic Agents in Preclinical Tumor Models. Mol Cancer Ther. 2015;14(4):931-40.

44. Chakrabarty A, Sanchez V, Kuba MG, Rinehart C, Arteaga CL. Feedback upregulation of HER3 (ErbB3) expression and activity attenuates antitumor effect of PI3K inhibitors. Proc Natl Acad Sci U S A. 2012;109(8):2718-23.

45. Chakrabarty A, Bhola NE, Sutton C, Ghosh R, Kuba MG, Dave B, et al. Trastuzumab-resistant cells rely on a HER2-PI3K-FoxO-survivin axis and are sensitive to PI3K inhibitors. Cancer Res. 2013;73(3):1190-200.

46. Brown JR, Davids MS, Rodon J, Abrisqueta P, Kasar SN, Lager J, et al. Phase I Trial of the Pan-PI3K Inhibitor Pilaralisib (SAR245408/XL147) in Patients with Chronic Lymphocytic Leukemia (CLL) or Relapsed/Refractory Lymphoma. Clin Cancer Res. 2015;21(14):3160-9.

47. Tolaney S, Burris H, Gartner E, Mayer IA, Saura C, Maurer M, et al. Phase I/II study of pilaralisib (SAR245408) in combination with trastuzumab or trastuzumab plus paclitaxel in trastuzumab-refractory HER2-positive metastatic breast cancer. Breast Cancer Res Treat. 2015;149(1):151-61.

48. Matulonis U, Vergote I, Backes F, Martin LP, McMeekin S, Birrer M, et al. Phase II study of the PI3K inhibitor pilaralisib (SAR245408; XL147) in patients with advanced or recurrent endometrial carcinoma. Gynecol Oncol. 2015; 136(2):246-53.

49. Cloughesy TF, Mischel PS, Omuro AMP, Prados M, Wen PY, Wu B, et al Tumor pharmacokinetics (PK) and pharmacodynamics (PD) of SAR245409 (XL765) and SAR245408 (XL147) administered as single agents to patients with recurrent glioblastoma (GBM): An Ivy Foundation early-phase clinical trials consortium study [abstract]. J Clin Oncol. 2013;31:2012.

50. Ihle NT, Williams R, Chow S, Chew W, Berggren MI, Paine-Murrieta G, et al. Molecular pharmacology and antitumor activity of PX-866, a novel inhibitor of phosphoinositide-3-kinase signaling. Mol Cancer Ther. 2004;3(7):763-72.

51. Howes AL, Chiang GG, Lang ES, Ho CB, Powis G, Vuori $\mathrm{K}$, et al. The phosphatidylinositol 3-kinase inhibitor, PX-866, is a potent inhibitor of cancer cell motility and growth in three-dimensional cultures. Mol Cancer Ther. 2007;6(9):2505-14.

52. Ihle NT, Paine-Murrieta G, Berggren MI, Baker A, Tate WR, Wipf $P$, et al. The phosphatidylinositol-3-kinase inhibitor PX-866 overcomes resistance to the epidermal growth factor receptor inhibitor gefitinib in A-549 human non-small cell lung cancer xenografts. Mol Cancer Ther. 2005;4(9):1349-57.

53. Ihle NT, Lemos R, Schwartz D, Oh J, Halter RJ, Wipf $P$, et al. Peroxisome proliferator-activated receptor gamma agonist pioglitazone prevents the hyperglycemia caused by phosphatidylinositol 3-kinase pathway inhibition by PX-866 without affecting antitumor activity. Mol Cancer Ther. 2009;8(1):94-100.

54. Ihle NT, Lemos R Jr, Wipf P, Yacoub A, Mitchell C, Siwak D, et al. Mutations in the phosphatidylinositol-3-kinase pathway predict for antitumor activity of the inhibitor PX-866 whereas oncogenic Ras is a dominant predictor for resistance. Cancer Res. 2009;69(1):143-50.
55. Koul D, Shen R, Kim YW, Kondo Y, Lu Y, Bankson J, et al. Cellular and in vivo activity of a novel PI3K inhibitor, PX-866, against human glioblastoma. Neuro Oncol. 2010;12(6):559-69.

56. Gwak HS, Shingu T, Chumbalkar V, Hwang YH, DeJournett R, Latha K, et al. Combined action of the dinuclear platinum compound BBR3610 with the PI3-K inhibitor PX-866 in glioblastoma. Int J Cancer. 2011;128(4):787-96.

57. Levy B, Spira A, Becker D, Evans T, Schnadig I, Camidge DR, et al. A randomized, phase 2 trial of Docetaxel with or without PX-866, an irreversible oral phosphatidylinositol 3-kinase inhibitor, in patients with relapsed or metastatic non-small-cell lung cancer. J Thorac Oncol. 2014:9(7):1031-5.

58. Bowles DW, Ma WW, Senzer N, Brahmer JR, Adjei AA, Davies M, et al. A multicenter phase 1 study of PX-866 in combination with docetaxel in patients with advanced solid tumours. Br J Cancer. 2013;109(5):1085-92.

59. Hong DS, Bowles DW, Falchook GS, Messersmith WA, George GC, O'Bryant $\mathrm{CL}$, et al. A multicenter phase I trial of PX-866, an oral irreversible phosphatidylinositol 3-kinase inhibitor, in patients with advanced solid tumors. Clin Cancer Res. 2012;18(15):4173-82.

60. Bowles DW, Kochenderfer M, Cohn A, Sideris L, Nguyen N, Cline-Burkhardt V, et al. A Randomized, Phase II Trial of Cetuximab With or Without PX-866, an Irreversible Oral Phosphatidylinositol 3-Kinase Inhibitor, in Patients With Metastatic Colorectal Carcinoma. Clin Colorectal Cancer. 2016;

61. Jimeno A, Shirai K, Choi M, Laskin J, Kochenderfer M, Spira A, et al. A randomized, phase II trial of cetuximab with or without PX-866, an irreversible oral phosphatidylinositol 3-kinase inhibitor, in patients with relapsed or metastatic head and neck squamous cell cancer. Ann Oncol. 2015;26(3):556-61.

62. Pitz MW, Eisenhauer EA, MacNeil MV, Thiessen B, Easaw JC, Macdonald DR et al. Phase II study of PX-866 in recurrent glioblastoma. Neuro-Oncology. 2015:17(9):1270-4.

63. Raynaud Fl, Eccles SA, Patel S, Alix S, Box G, Chuckowree I, et al. Biological properties of potent inhibitors of class I phosphatidylinositide 3-kinases: from PI-103 through PI-540, PI-620 to the oral agent GDC-0941. Mol Cancer Ther. 2009:8(7):1725-38.

64. Pareja F, Macleod D, Shu C, Crary JF, Canoll PD, Ross AH, et al. PI3K and BCl2 inhibition primes glioblastoma cells to apoptosis through downregulation of Mcl-1 and Phospho-BAD. Mol Cancer Res. 2014;12(7):987-1001.

65. Enzenmuller S, Gonzalez P, Karpel-Massler G, Debatin KM, Fulda S. GDC-0941 enhances the lysosomal compartment via TFEB and primes glioblastoma cells to lysosomal membrane permeabilization and cell death. Cancer Lett. 2013:329(1):27-36

66. Salphati L, Shahidi-Latham S, Quiason C, Barck K, Nishimura M, Alicke B, et al. Distribution of the phosphatidylinositol 3-kinase inhibitors Pictilisib (GDC0941) and GNE-317 in U87 and GS2 intracranial glioblastoma modelsassessment by matrix-assisted laser desorption ionization imaging. Drug Metab Dispos. 2014;42(7):1110-6

67. Nonnenmacher L, Westhoff MA, Fulda S, Karpel-Massler G, Halatsch ME, Engelke J, et al. RIST: a potent new combination therapy for glioblastoma. Int J Cancer. 2015:136(4):E173-87.

68. Lin L, Gaut D, Hu K, Yan H, Yin D, Koeffler HP. Dual targeting of glioblastoma multiforme with a proteasome inhibitor (Velcade) and a phosphatidylinositol 3-kinase inhibitor (ZSTK474). Int J Oncol. 2014;44(2):557-62.

69. Rewcastle GW, Gamage SA, Flanagan JU, Kendall JD, Denny WA, Baguley $B C$, et al. Synthesis and biological evaluation of novel phosphatidylinosito 3-kinase inhibitors: Solubilized 4-substituted benzimidazole analogs of 2(difluoromethyl)-1-[4,6-di(4-morpholinyl)-1,3,5-triazin-2-yl]-1H-benzimidazole (ZSTK474). Eur J Med Chem. 2013;64:137-47.

70. Norman MH, Andrews KL, Bo YY, Booker SK, Caenepeel S, Cee VJ, et al. Selective class I phosphoinositide 3-kinase inhibitors: optimization of a series of pyridyltriazines leading to the identification of a clinical candidate, AMG 511. J Med Chem. 2012;55(17):7796-816

71. Zumsteg ZS, Morse N, Krigsfeld G, Gupta G, Higginson DS, Lee NY, et al. Taselisib (GDC-0032), a Potent beta-Sparing Small Molecule Inhibitor of PI3K, Radiosensitizes Head and Neck Squamous Carcinomas Containing Activating PIK3CA Alterations. Clin Cancer Res. 2016;22(8):2009-19.

72. Lopez S, Schwab CL, Cocco E, Bellone S, Bonazzoli E, English DP, et al. Taselisib, a selective inhibitor of PIK3CA, is highly effective on PIK3CAmutated and HER2/neu amplified uterine serous carcinoma in vitro and in vivo. Gynecol Oncol. 2014;135(2):312-7

73. Liu N, Rowley BR, Bull CO, Schneider C, Haegebarth A, Schatz CA, et al. BAY 80-6946 is a highly selective intravenous PI3K inhibitor with potent 
p110alpha and p110delta activities in tumor cell lines and xenograft models. Mol Cancer Ther. 2013;12(11):2319-30.

74. Elster N, Cremona M, Morgan C, Toomey S, Carr A, O'Grady A, et al. A preclinical evaluation of the PI3K alpha/delta dominant inhibitor BAY 806946 in HER2-positive breast cancer models with acquired resistance to the HER2-targeted therapies trastuzumab and lapatinib. Breast Cancer Res Treat. 2015;149(2):373-83.

75. Furet $\mathrm{P}$, Guagnano V, Fairhurst RA, Imbach-Weese $\mathrm{P}$, Bruce I, Knapp M, et al. Discovery of NVP-BYL719 a potent and selective phosphatidylinositol-3 kinase alpha inhibitor selected for clinical evaluation. Bioorg Med Chem Lett. 2013;23(13):3741-8.

76. Bosch A, Li Z, Bergamaschi A, Ellis H, Toska E, Prat A, et al. PI3K inhibition results in enhanced estrogen receptor function and dependence in hormone receptor-positive breast cancer. Sci Transl Med. 2015;7(283):283ra51.

77. Wong $\mathrm{CH}, \mathrm{Ma} \mathrm{BB}$, Cheong HT, Hui CW, Hui EP, Chan AT. Preclinical evaluation of PI3K inhibitor BYL719 as a single agent and its synergism in combination with cisplatin or MEK inhibitor in nasopharyngeal carcinoma (NPC). Am J Cancer Res. 2015;5(4):1496-506.

78. Bonelli MA, Cavazzoni A, Saccani F, Alfieri RR, Quaini F, La Monica S, et al. Inhibition of PI3K Pathway Reduces Invasiveness and Epithelial-toMesenchymal Transition in Squamous Lung Cancer Cell Lines Harboring PIK3CA Gene Alterations. Mol Cancer Ther. 2015;14(8):1916-27.

79. Fritsch C, Huang A, Chatenay-Rivauday C, Schnell C, Reddy A, Liu M, et al. Characterization of the novel and specific PI3Kalpha inhibitor NVP-BYL719 and development of the patient stratification strategy for clinical trials. Mol Cancer Ther. 2014;13(5):1117-29.

80. Dejan Juric, Johann Sebastian De Bono, Patricia LoRusso, John J Nemunaitis, Elisabeth I Heath, Eunice Lee Kwak, et al. First-in-human, phase I, doseescalation study of selective PI3Ka isoform inhibitor MLN1117 in patients (pts) with advanced solid malignancies [abstract]. J Clin Oncol. 2015;33.

81. Aurelius Gabriel Omlin, James F. Spicer, Debashis Sarker, David James Pinato, Roshan Agarwal, Philippe Alexandre Cassier, et al. A pharmacokinetic (PK) pharmacodynamic (PD) driven first-in-human study of the oral class I PI3K inhibitor CH5132799, in patients with advanced solid tumors [abstract]. J Clin Oncol. 2012;30

82. Hendrik-Tobias Arkenau, Joaquin Mateo, Charlotte Rose Lemech, Jeffrey R Infante, Howard A Burris, Yung-Jue Bang, et al. A phase I/II, first-in-human dose-escalation study of GSK2636771 in patients (pts) with PTEN-deficient advanced tumors [abstract]. J Clin Oncol. 2014;32.

83. Faivre S, Kroemer G, Raymond E. Current development of mTOR inhibitors as anticancer agents. Nat Rev Drug Discov. 2006;5(8):671-88.

84. Franz DN, Belousova E, Sparagana S, Bebin EM, Frost M, Kuperman R, et al. Everolimus for subependymal giant cell astrocytoma in patients with tuberous sclerosis complex: 2-year open-label extension of the randomised EXIST-1 study. Lancet Oncol. 2014;15(13):1513-20.

85. Kwitkowski VE, Prowell TM, Ibrahim A, Farrell AT, Justice R, Mitchell SS, et al. FDA approval summary: temsirolimus as treatment for advanced renal cell carcinoma. Oncologist. 2010;15(4):428-35.

86. Sarbassov DD, Ali SM, Kim DH, Guertin DA, Latek RR, Erdjument-Bromage $H$, et al. Rictor, a novel binding partner of $\mathrm{mTOR}$, defines a rapamycin-insensitive and raptor-independent pathway that regulates the cytoskeleton. Curr Biol. 2004; 14(14):1296-302.

87. O'Reilly KE, Rojo F, She QB, Solit D, Mills GB, Smith D, et al. mTOR inhibition induces upstream receptor tyrosine kinase signaling and activates Akt. Cancer Res. 2006;66(3):1500-8.

88. Kharas MG, Janes MR, Scarfone VM, Lilly MB, Knight ZA, Shokat KM, et al. Ablation of PI3K blocks BCR-ABL leukemogenesis in mice, and a dual PI3K mTOR inhibitor prevents expansion of human BCR-ABL+ leukemia cells. J Clin Inv. 2008;118(9):3038-50

89. Yu Z, Xie G, Zhou G, Cheng Y, Zhang G, Yao G, et al. NVP-BEZ235, a novel dual PI3K-mTOR inhibitor displays anti-glioma activity and reduces chemoresistance to temozolomide in human glioma cells. Cancer Lett. 2015;367(1):58-68.

90. Dey N, Sun Y, Carlson JH, Wu H, Lin X, Leyland-Jones B, et al. Anti-tumor efficacy of BEZ235 is complemented by its anti-angiogenic effects via downregulation of PI3K-mTOR-HIF1alpha signaling in HER2-defined breast cancers. Am J Cancer Res. 2016;6(4):714-46.

91. Roper J, Richardson MP, Wang WV, Richard LG, Chen W, Coffee EM, et al. The dual PI3K/mTOR inhibitor NVP-BEZ235 induces tumor regression in a genetically engineered mouse model of PIK3CA wild-type colorectal cancer. PLoS One. 2011;6(9):e25132.
92. Sano T, Takeuchi S, Nakagawa T, Ishikawa D, Nanjo S, Yamada T, et al. The novel phosphoinositide 3-kinase-mammalian target of rapamycin inhibitor, BEZ235, circumvents erlotinib resistance of epidermal growth factor receptor mutant lung cancer cells triggered by hepatocyte growth factor. Int J Cancer. 2013;133(2):505-13.

93. Gil del Alcazar CR, Hardebeck MC, Mukherjee B, Tomimatsu N, Gao X, Yan J, et al. Inhibition of DNA double-strand break repair by the dual PI3K/mTOR inhibitor NVP-BEZ235 as a strategy for radiosensitization of glioblastoma. Clin Cancer Res. 2014;20(5):1235-48.

94. Kuger S, Graus D, Brendtke R, Gunther N, Katzer A, Lutyj P, et al. Radiosensitization of Glioblastoma Cell Lines by the Dual PI3K and mTOR Inhibitor NVP-BEZ235 Depends on Drug-Irradiation Schedule. Transl Oncol. 2013:6(2):169-79.

95. Sunayama J, Sato A, Matsuda K, Tachibana K, Suzuki K, Narita Y, et al. Dual blocking of mTor and PI3K elicits a prodifferentiation effect on glioblastoma stem-like cells. Neuro Oncol. 2010;12(12):1205-19.

96. Sunayama J, Matsuda K, Sato A, Tachibana K, Suzuki K, Narita Y, et al. Crosstalk between the PI3K/mTOR and MEK/ERK pathways involved in the maintenance of self-renewal and tumorigenicity of glioblastoma stem-like cells. Stem Cells. 2010;28(11):1930-9.

97. Fazio N, Buzzoni R, Baudin E, Antonuzzo L, Hubner RA, Lahner H, et al. A Phase II Study of BEZ235 in Patients with Everolimus-resistant, Advanced Pancreatic Neuroendocrine Tumours. Anticancer Res. 2016;36(2):713-9.

98. Bendell JC, Kurkjian C, Infante JR, Bauer TM, Burris HA 3rd, Greco FA, et al. A phase 1 study of the sachet formulation of the oral dual PI3K/mTOR inhibitor BEZ235 given twice daily (BID) in patients with advanced solid tumors. Investig New Drugs. 2015;33(2):463-71.

99. Wise-Draper TM, Moorthy G, Salkeni MA, Karim NA, Thomas HE, Mercer CA, et al. A Phase lb Study of the Dual PI3K/mTOR Inhibitor Dactolisib (BEZ235) Combined with Everolimus in Patients with Advanced Solid Malignancies. Target Oncol. 2017 [Epub ahead of print].

100. Yu P, Laird AD, Du X, Wu J, Won KA, Yamaguchi K, et al. Characterization of the activity of the PI3K/mTOR inhibitor XL765 (SAR245409) in tumor models with diverse genetic alterations affecting the PI3K pathway. Mol Cancer Ther. 2014;13(5):1078-91.

101. Prasad G, Sottero T, Yang X, Mueller S, James CD, Weiss WA, et al. Inhibition of PI3K/mTOR pathways in glioblastoma and implications for combination therapy with temozolomide. Neuro-Oncology. 2011;13(4):384-92.

102. Papadopoulos KP, Tabernero J, Markman B, Patnaik A, Tolcher AW, Baselga J, et al. Phase I safety, pharmacokinetic, and pharmacodynamic study of SAR245409 (XL765), a novel, orally administered PI3K/mTOR inhibitor in patients with advanced solid tumors. Clin Cancer Res. 2014;20(9):2445-56.

103. Wen PY, Omuro A, Ahluwalia MS, Fathallah-Shaykh HM, Mohile N, Lager J, et al. Phase I dose-escalation study of the PI3K/mTOR inhibitor voxtalisib (SAR245409, XL765) plus temozolomide with or without radiotherapy in patients with high-grade glioma. Neuro-Oncology. 2015;17(9):1275-83.

104. Heffron TP, Ndubaku CO, Salphati L, Alicke B, Cheong J, Drobnick J, et al. Discovery of Clinical Development Candidate GDC-0084, a Brain Penetrant Inhibitor of PI3K and mTOR. ACS Med Chem Lett. 2016;7(4):351-6.

105. Wen PY, Cloughesy TF, Olivero A, Lu X, Mueller L, Coimbra AF, et al. A firstin-human phase 1 study to evaluate the brain-penetrant PI3K/mTOR inhibitor GDC-0084 in patients with progressive or recurrent high-grade glioma [abstract]. J Clin Oncol. 2016;34:2012.

106. Vladimir Cmiljanovic, Robert A Ettlin, Florent Beaufils, Walter Dieterle, Petra Hillmann, Juergen Mestan, et al. PQR309: A potent, brain-penetrant, dual pan-PI3K/mTOR inhibitor with excellent oral bioavailability and tolerability [abstract]. In: Proceedings of the 106th Annual Meeting of the American Association for Cancer Research Philadelphia: AACR; Cancer Res 2015. 75(15 Suppl):4514

107. Kristeleit RS, Brown NF, Hess D, Joerger M, Von Moos R, Rodón J, et al. A phase 1 first-in-human $(F \mid H)$ dose-escalation (DE) study of the oral dual PI3K/mTOR inhibitor PQR309 in patients (pts) with advanced solid tumors: Final DE results [abstract]. J Clin Oncol. 2015;33:2592.

108. Adjei AA, Dy GK, Zhao Y, Ma WW, Opyrchal M, Bakhribah H, et al. A phase 1 study of the PI3K/mTOR inhibitor PQR309 evaluating safety, pharmacokinetics (PK) and pharmacodynamics (PD) in patients (pts) with advanced solid tumors [abstract]. J Clin Oncol. 2016;34:2560.

109. Young CD, Pfefferle AD, Owens P, Kuba MG, Rexer BN, Balko JM, et al. Conditional loss of ErbB3 delays mammary gland hyperplasia induced by mutant PIK3CA without affecting mammary tumor latency, gene expression, or signaling. Cancer Res. 2013;73(13):4075-85. 
110. She QB, Gruvberger-Saal SK, Maurer M, Chen Y, Jumppanen M, Su T, et al. Integrated molecular pathway analysis informs a synergistic combination therapy targeting PTEN/PI3K and EGFR pathways for basal-like breast cancer. BMC Cancer. 2016;16:587.

111. Zhu Y, Shah K. Multiple lesions in receptor tyrosine kinase pathway determine glioblastoma response to pan-ERBB inhibitor PF-00299804 and PI3K/mTOR dual inhibitor PF-05212384. Cancer Biol Ther. 2014;15(6):815-22.

112. Saura C, Bendell J, Jerusalem G, Su S, Ru Q, De Buck S, et al. Phase Ib study of Buparlisib plus Trastuzumab in patients with HER2-positive advanced or metastatic breast cancer that has progressed on Trastuzumab-based therapy. Clin Cancer Res. 2014;20(7):1935-45.

113. Soria JC, LoRusso P, Bahleda R, Lager J, Liu L, Jiang J, et al. Phase I dose-escalation study of pilaralisib (SAR245408, XL147), a pan-class I PI3K inhibitor, in combination with erlotinib in patients with solid tumors. Oncologist. 2015;20(3):245-6.

114. Castellano E, Downward J. RAS Interaction with PI3K: More Than Just Another Effector Pathway. Genes Cancer. 2011:2(3):261-74.

115. Engelman JA, Chen L, Tan X, Crosby K, Guimaraes AR, Upadhyay R, et al. Effective use of PI3K and MEK inhibitors to treat mutant Kras G12D and PIK3CA H1047R murine lung cancers. Nat Med. 2008;14(12):1351-6.

116. El Meskini R, lacovelli AJ, Kulaga A, Gumprecht M, Martin PL, Baran M, et al. A preclinical orthotopic model for glioblastoma recapitulates key features of human tumors and demonstrates sensitivity to a combination of MEK and PI3K pathway inhibitors. Dis Models Mech. 2015;8(1):45-56.

117. Zhao HF, Wang J, Tony To SS. The phosphatidylinositol 3-kinase/Akt and c-Jun N-terminal kinase signaling in cancer: Alliance or contradiction? (Review). Int J Oncol. 2015;47(2):429-36.

118. Shimizu T, Tolcher AW, Papadopoulos KP, Beeram M, Rasco DW, Smith LS, et al. The clinical effect of the dual-targeting strategy involving PI3K/AKT/ mTOR and RAS/MEKJERK pathways in patients with advanced cancer. Clin Cancer Res. 2012;18(8):2316-25

119. Bedard PL, Tabernero J, Janku F, Wainberg ZA, Paz-Ares L, Vansteenkiste J, et al. A phase $\mathrm{lb}$ dose-escalation study of the oral pan-PI3K inhibitor buparlisib (BKM120) in combination with the oral MEK1/2 inhibitor trametinib (GSK1120212) in patients with selected advanced solid tumors. Clin Cancer Res. 2015;21(4):730-8.

120. Filbin MG, Dabral SK, Pazyra-Murphy MF, Ramkissoon S, Kung AL, Pak E, et al. Coordinate activation of Shh and PI3K signaling in PTEN-deficient glioblastoma: new therapeutic opportunities. Nat Med. 2013;19(11):1518-23.

121. Sharma N, Nanta R, Sharma J, Gunewardena S, Singh KP, Shankar S, et al. $\mathrm{PI} 3 \mathrm{~K} / \mathrm{AKT} / \mathrm{mTOR}$ and sonic hedgehog pathways cooperate together to inhibit human pancreatic cancer stem cell characteristics and tumor growth. Oncotarget. 2015;6(31):32039-60.

122. Wei L, Xu Z. Cross-signaling among phosphinositide-3 kinase, mitogenactivated protein kinase and sonic hedgehog pathways exists in esophageal cancer. Int J Cancer. 2011;129(2):275-84

123. Ramaswamy B, Lu Y, Teng KY, Nuovo G, Li X, Shapiro CL, et al. Hedgehog signaling is a novel therapeutic target in tamoxifen-resistant breast cancer aberrantly activated by PI3K/AKT pathway. Cancer Res. 2012;72(19):5048-59.

124. Metcalfe C, Alicke B, Crow A, Lamoureux M, Dijkgraaf GJ, Peale F, et al. PTEN loss mitigates the response of medulloblastoma to Hedgehog pathway inhibition. Cancer Res. 2013;73(23):7034-42.

125. Chu QS, Mahipal A, Schuler M, De Braud FGM, Dirix L, Rampersad A, et al. Dose-escalation study of sonidegib (LDE225) plus buparlisib (BKM120) in patients (pts) with advanced solid tumors [abstract]. Ann Oncol. 2014; 25(Supplement 4):iv147-iv8.

126. Liu P, Cheng H, Santiago S, Raeder M, Zhang F, Isabella A, et al. Oncogenic PIK3CA-driven mammary tumors frequently recur via PI3K pathway-dependent and PI3K pathway-independent mechanisms. Nat Med. 2011;17(9):1116-20.

127. Leten C, Struys T, Dresselaers T, Himmelreich U. In vivo and ex vivo assessment of the blood brain barrier integrity in different glioblastoma animal models. J Neuro-Oncol. 2014;119(2):297-306.

128. van Tellingen $O$, Yetkin-Arik B, de Gooijer MC, Wesseling P, Wurdinger T, de Vries HE. Overcoming the blood-brain tumor barrier for effective glioblastoma treatment. Drug Resist Updat. 2015;19:1-12

129. Miller BW, Przepiorka D, de Claro RA, Lee K, Nie L, Simpson N, et al. FDA approval: idelalisib monotherapy for the treatment of patients with follicular lymphoma and small lymphocytic lymphoma. Clin Cancer Res. 2015;21(7):1525-9.

130. Folkes AJ, Ahmadi K, Alderton WK, Alix S, Baker SJ, Box G, et al. The identification of 2-(1H-indazol-4-yl)-6-(4-methanesulfonyl-piperazin-1ylmethyl)-4-morpholin-4-yl-t hieno[3,2-d]pyrimidine (GDC-0941) as a potent, selective, orally bioavailable inhibitor of class I PI3 kinase for the treatment of cancer. J Med Chem. 2008;51(18):5522-32.

131. Ndubaku CO, Heffron TP, Staben ST, Baumgardner M, Blaquiere N, Bradley $E_{,}$ et al. Discovery of 2-\{3-[2-(1-isopropyl-3-methyl-1H-1,2-4-triazol-5-yl)-5,6dihydrobenzo[f]imidazo[1,2-d][1,4]oxazepin-9-yl]-1H-pyrazol-1-yl\}-2methylpropanamide (GDC-0032): a beta-sparing phosphoinositide 3-kinase inhibitor with high unbound exposure and robust in vivo antitumor activity. Med Chem. 2013;56(11):4597-610.

132. Scott WJ, Hentemann MF, Rowley RB, Bull CO, Jenkins S, Bullion AM, et al. Discovery and SAR of Novel 2,3-Dihydroimidazo[1,2-c]quinazoline PI3K Inhibitors: Identification of Copanlisib (BAY 80-6946). ChemMedChem. 2016;11(14):1517-30.

133. Kong D, Yamori T. ZSTK474 is an ATP-competitive inhibitor of class I phosphatidylinositol 3 kinase isoforms. Cancer Sci. 2007;98(10):1638-42.

134. Lannutti BJ, Meadows SA, Herman SEM, Kashishian A, Steiner B, Johnson AJ, et al. CAL-101, a p110 selective phosphatidylinositol-3-kinase inhibitor for the treatment of B-cell malignancies, inhibits PI3K signaling and cellular viability. Blood. 2010;117(2):591-4.

135. Cushing TD, Hao X, Shin Y, Andrews K, Brown M, Cardozo M, et al. Discovery and in vivo evaluation of (S)-N-(1-(7-fluoro-2-(pyridin-2-yl)quinolin3-yl)ethyl)-9H-purin-6-amine (AMG319) and related PI3Kdelta inhibitors for inflammation and autoimmune disease. J Med Chem. 2015;58(1):480-511.

136. Nylander S, Kull B, Bjorkman JA, Ulvinge JC, Oakes N, Emanuelsson BM, et al. Human target validation of phosphoinositide 3-kinase (PI3K)beta: effects on platelets and insulin sensitivity, using AZD6482 a novel PI3Kbeta inhibitor. J Thromb Haemost. 2012:10(10):2127-36.

137. Ohwada J, Ebiike H, Kawada H, Tsukazaki M, Nakamura M, Miyazaki T, et al. Discovery and biological activity of a novel class I PI3K inhibitor, CH5132799. Bioorg Med Chem Lett. 2011;21(6):1767-72.

138. Camps M, Ruckle T, Ji H, Ardissone V, Rintelen F, Shaw J, et al. Blockade of PI3Kgamma suppresses joint inflammation and damage in mouse models of rheumatoid arthritis. Nat Med. 2005;11(9):936-43.

139. So L, Yea SS, Oak JS, Lu M, Manmadhan A, Ke QH, et al. Selective inhibition of phosphoinositide 3-kinase p110alpha preserves lymphocyte function. J Biol Chem. 2013;288(8):5718-31.

140. Maira SM, Stauffer F, Brueggen J, Furet P, Schnell C, Fritsch C, et al. Identification and characterization of NVP-BEZ235, a new orally available dual phosphatidylinositol 3-kinase/mammalian target of rapamycin inhibitor with potent in vivo antitumor activity. Mol Cancer Ther. 2008;7(7):1851-63.

141. Markman B, Tabernero J, Krop I, Shapiro GI, Siu L, Chen LC, et al. Phase I safety, pharmacokinetic, and pharmacodynamic study of the oral phosphatidylinositol-3-kinase and mTOR inhibitor BGT226 in patients with advanced solid tumors. Ann Oncol. 2012;23(9):2399-408.

142. Knight SD, Adams ND, Burgess JL, Chaudhari AM, Darcy MG, Donatelli CA, et al. Discovery of GSK2126458, a Highly Potent Inhibitor of PI3K and the Mammalian Target of Rapamycin. ACS Med Chem Lett. 2010;1(1):39-43.

143. Maira SM, Finan P, Garcia-Echeverria C. From the bench to the bed side: PI3K pathway inhibitors in clinical development. Curr Top Microbiol Immunol. 2010;347:209-39.

144. Sutherlin DP, Bao L, Berry M, Castanedo G, Chuckowree I, Dotson J, et al. Discovery of a potent, selective, and orally available class I phosphatidylinositol 3-kinase (PI3K)/mammalian target of rapamycin (mTOR) kinase inhibitor (GDC-0980) for the treatment of cancer. J Med Chem. 2011:54(21):7579-87.

145. Hart S, Novotny-Diermayr V, Goh KC, Williams M, Tan YC, Ong LC, et al. VS-5584, a novel and highly selective PI3K/mTOR kinase inhibitor for the treatment of cancer. Mol Cancer Ther. 2013;12(2):151-61.

146. Yuan J, Mehta PP, Yin MJ, Sun S, Zou A, Chen J, et al. PF-04691502, a potent and selective oral inhibitor of PI3K and mTOR kinases with antitumor activity. Mol Cancer Ther. 2011:10(11):2189-99.

147. Venkatesan AM, Dehnhardt CM, Delos Santos E, Chen Z, Dos Santos O, Ayral-Kaloustian S, et al. Bis(morpholino-1,3,5-triazine) derivatives: potent adenosine 5'-triphosphate competitive phosphatidylinositol-3-kinase/ mammalian target of rapamycin inhibitors: discovery of compound 26 (PKI587), a highly efficacious dual inhibitor. J Med Chem. 2010;53(6):2636-45.

148. Mallon R, Hollander I, Feldberg L, Lucas J, Soloveva V, Venkatesan A, et al. Antitumor efficacy profile of PKI-402, a dual phosphatidylinositol 3-kinase/ mammalian target of rapamycin inhibitor. Mol Cancer Ther. 2010;9(4):976-84. 